City University of New York (CUNY) CUNY Academic Works

2012

\title{
A New Nonlinear Analytical Model for Canopy Flow over a Forested Hill
}

Weiguo Wang

National Oceanic and Atmospheric Administration

Chuixiang Yi

CUNY Queens College

\section{How does access to this work benefit you? Let us know!}

More information about this work at: https://academicworks.cuny.edu/qc_pubs/273

Discover additional works at: https://academicworks.cuny.edu

This work is made publicly available by the City University of New York (CUNY).

Contact: AcademicWorks@cuny.edu 


\section{A new nonlinear analytical model for canopy flow over a forested hill}

Weiguo Wang $^{1}$ and Chuixiang $\mathrm{Yi}^{2}$

${ }^{1}$ IMSG@EMC/NCEP/NOAA, Camp Springs, MD 20746

${ }^{2}$ Queens College, City University of New York, Flushing, New York, USA

Correspondence: Chuixiang Yi

School of Earth and Environmental Sciences

Queens College, City University of New York

65-30 Kissena Blvd

Flushing, New York 11367

Phone: (718) 997-3366

Fax: (718) 997-3299

E-mail: cyi@qc.cuny.edu 
Abstract: A new nonlinear analytical model for canopy flow over gentle hills is presented. This model is established based on the assumption that three major forces (pressure gradient, Reynolds stress gradient, and nonlinear canopy drag) within canopy are in balance for gentle hills under neutral conditions. The momentum governing equation is closed by the velocity-squared law. This new model has many advantages over the model developed by Finnigan and Belcher (2004, hereafter referred to as FB04) in predicting canopy wind velocity profiles in forested hills in that: (1) this model predictions are more realistic because the surface drag can be taken into account by boundary conditions, while surface drag effects cannot be accounted for in the algebraic equation used in the lower canopy layer in the FB04 model; (2) the mixing-length theory is not necessarily used because it leads to a theoretical inconsistency that a constant mixing-length assumption leads to a non-constant mixing-length prediction as in the FB04 model; and (3) the effects of height-dependent leaf area density $(a(z))$ and drag coefficient $\left(C_{d}\right)$ on wind velocity can be predicted, while both $a(z)$ and $C_{d}$ must be treated as constants in FB04 model. The nonlinear algebraic equation for momentum transfer in the lower part of canopy used in FB04 model is height-independent, actually serving as a bottom boundary condition for the linear differential momentum equation in the upper canopy layer. The predicting ability of the FB04 model is largely restricted by using the height-independent algebraic equation in the bottom canopy layer. This study has demonstrated the success of using the velocity-squared law as a closure scheme for momentum transfer in forested hills in comparison with the mixing-length theory used in FB04 model thus enhancing the predicting ability of canopy flows, keeping the theory consistent and simple, and shining a new light into land-surface parameterization schemes in numerical weather and climate models.

\section{Keywords: Canopy flow model; Complex terrain; Leaf area density; Wind profile}




\section{Introduction}

The real world surface is not flat and most of it is covered by vegetation. Analytical research into flows within and above vegetation of a forested hill has many implications such as: (1) improving the land surface parameterization of numerical weather prediction models (e.g., Hunt et al. 1988; Belcher et al. 1993; Kaimal and Finnigan 1994; Belcher and Hunt 1998; Wood 2000); (2) theoretical understanding of mechanisms behind the advection problem in eddy-flux measurements (e.g., Goulden et al. 1996; Lee 1998; Massman and Lee 2002; Aubinet et al. 2003; Feigenwinter et al. 2004; Staebler and Fitzjarrald 2004; Wang et al. 2005, 2006, 2007; Yi et al. 2005; Sun et al. 2007, 2010; Feigenwinter et al. 2008; Finnigan 2008; Kutch et al. 2008; Wang and Davis 2008; Yi et al. 2008; Yi 2009; Wang 2010; Wang and Rotach 2010; Burns et al., 2011; Wang 2012); and (3) modeling complex exchange between forests and atmosphere (Wolfe and Thornton, 2011; Wolfe et al., 2011; Edburg et al., 2010; Queck and Bernhofer, 2010).

The theoretical foundation of analytical studies of airflows over a forested hill was formulated mainly by Jackson and Hunt (1975) (hereafter referred to as JH75), though improvements have been made since then (e.g. Sykes 1978; Hunt and Richards 1984; Hunt et al. 1988; Hunt and Carruthers 1990; Belcher et al. 1993; Belcher and Hunt 1998). To theoretically understand the perturbations produced by rough hills to mean flow and pressure fields, JH75 divided an atmospheric boundary layer into two layers; namely, a thin inner layer that is adjacent to a surface where Reynolds stress gradients play a significant role and a deeper outer layer where Reynolds stress gradients are negligible. With a linear approximation, JH75 derived an analytical solution of the perturbation wind field in each layer. The predictions of JH75's linear theory have been broadly supported by observations (e.g. Mason and Sykes 1979; Bradley 1980; Mason and King 1985; Taylor and Teunissen 1987; Salmon et al. 1988). Analytical solutions 
have been limited to gentle hill conditions because nonlinear effects become more significant for steeper hills.

Recent progress in analytical studies of airflows over gentle hills covered with forest canopies was made by Finnigan and Belcher (2004) (henceforth FB04). Instead of using the roughness-length parameterization to represent canopy effects, FB04 coupled an analytical canopy model with the linear model of Hunt et al (1988) to simulate the wind field over forested hills. They divided a canopy layer into a linear layer in the upper part, governed by a linearized differential equation, and a nonlinear layer in the lower part, described by an algebraic equation. The mixing-length theory is used to parameterize the Reynolds stress term in both layers. It was further assumed that all of the mixing-length, leaf area density (LAD), and drag coefficient are constant throughout the canopy layer. FB04 model predicted that the presence of a canopy over a hill can lead to a reduced flow speed-up near the hill top, increased surface drag, and increased tendency for flow to separate within the canopy. These features have been supported by numerical simulations (Wood 2000; Brown et al. 2001; Allen and brown 2002; Ross and Vosper 2005; Dupont et al. 2008; Ross 2008) and validated by laboratory studies (Poggi and Katul 2007a, 2007b, 2007c; Poggi et al. 2008).

Nevertheless, the assumptions used in FB04 such as constant LAD and drag coefficient have restricted its application in reality. Moreover, the assumption of a constant mixing-length within a canopy is not consistent with the original mixing-length theory. This is because a mixing-length $\left(l_{m}\right)$ must satisfy Von Karman's rule (Von Karman 1930; Schlichting 1960; Tennekes and Lumley 1972), $l_{m}=\kappa\left|\frac{d U / d z}{d^{2} U / d z^{2}}\right|$, where $\kappa$ is von Karman's constant, $U$ is wind speed. Von Karman's rule indicates that a mixing length is a function of velocity distribution (Schlichting 1960). A typical velocity distribution for a forest canopy is S-shaped (Fons 1940; 
Lemon et al. 1970; Bergen 1971; Landsberg and James 1971; Oliver 1971; Shaw 1977; Meyers and Paw U 1986; Baldocchi and Meyers 1988; Fischenich 1996; Lalic and Mihailovic 2002; Turnipseed et al. 2003; Yi et al. 2005; Yi 2008). The mixing length of the S-shaped velocity distribution is not constant, being minimum at the local extreme values of the wind profile ( $\left.d U / d z=0, d^{2} U / d z^{2} \neq 0\right)$ and maximum at the inflection point of the wind profile ( $d U / d z \neq 0$, $d^{2} U / d z^{2}=0$ ). These characteristics (extreme values and inflection point) of in-canopy wind profile are predicted by FB04 model, varying from the windward side to leeward side of a forested hill. This means that the assumption of a constant mixing-length in the FB04 model leads to the prediction of a varying mixing-length. The mixing-length is not constant within canopy has been demonstrated by large-eddy simulations (Coceal et al. 2006; Ross 2008) and by water tank experiments (Poggi et al. 2007c). In addition, the no-slip condition at ground cannot be satisfied in FB04 model, leading to unrealistic predictions of wind profile in the lower canopy layer.

The goal of this paper is to enhance the ability of canopy wind predictions over forested hills by relaxing the restrictions and overcoming the theoretical inconsistency in the FB04 model. The essential difference between present and FB04 studies (Table 1) lies in the canopy flow model, in which we use the velocity-squared law as a closure scheme instead of the mixinglength theory used in FB04. With the new scheme, momentum transfer is governed by a single nonlinear differential equation throughout the canopy layer, constrained at the canopy top by the linear solution of JH75 model and at ground by the no-slip condition. Thus, knowledge about how ground surface drag, varying leaf area density, and canopy drag coefficient affect canopy flows over forested hills can be provided by the present model. 


\section{Canopy flow model and solutions over a gentle hill}

As in FB04, we consider the flow over a gentle hill covered by a dense canopy. The general framework of the present study is illustrated in Fig. 1. An atmospheric boundary layer is divided into inner and outer regions in the vertical (JH75 and Hunt et al. 1988). The inner region is further divided into two sublayers, i.e., within and above the canopy. We focus on the flow within the canopy and the proposed canopy flow model is briefly described below. Details of model assumptions and necessary formulas for canopy wind profile calculations are provided in the Appendix.

\subsection{Governing equation}

Over a flat surface, momentum balance within a canopy of height $h(-h<z<0)$ is approximately between turbulent stress gradient $(\tau)$ and canopy drag force $\left(F_{d}\right)$ (Inoue, 1963; Yi, 2008). Over a gentle and long hill, topography-induced horizontal pressure gradient $(P G)$, vertical gradient of turbulent stress, and canopy drag are in balance, with an assumption that advection terms can be neglected as argued in FB04. The streamwise momentum balance equation within the canopy can be written as,

$$
-P G+\frac{\partial \tau}{\partial z}-F_{d}=0
$$

with the boundary condition that both wind velocity and stress are continuous at the canopy top $(z=0)$. As in FB04, $P G$ is assumed to be invariant with height. With the parameterizations of $\tau$ and $F_{\mathrm{d}}$ used in Yi (2008, also see appendix), Eq. 1 can be rewritten as a closed ordinary differential equation,

$$
-P G(x)+\frac{\partial C_{d}(z) u(x, z)|u(x, z)|}{\partial z}-C_{d}(z) a(z) u(x, z)|u(x, z)|=0
$$


where $C_{\mathrm{d}}(z)$ is a canopy drag coefficient, $a(z)$ is $\mathrm{LAD}, u(x, z)$ is the horizontal wind velocity.

A general solution to the above equation can be expressed as

$$
C_{d}(z) u(x, z)|u(x, z)|=e^{\int a\left(z^{\prime}\right) d z^{\prime}}\left[P G(x) \int e^{\int a\left(z^{\prime \prime}\right) d z^{\prime \prime}} d z^{\prime}+C C\right],
$$

where $C C$ is a constant to be determined by the boundary condition. The solution suggests that the squared wind speed of canopy flow is proportional to $\mathrm{PG}$, inversely proportional to the drag coefficient, and may have a complicated relation with the distribution of $a(\mathrm{z})$. The analytical solution is critically dependent on solving the integral $\int a\left(z^{\prime}\right) d z^{\prime}$ for a given LAD profile (Massman 1982; 1997). To compare with the solution of the FB04 model, we first perform an analytical solution with a constant $a(z)$. Then we show an analytical solution for a simple heightvarying LAD distribution. Finally, the solution for arbitrary distributions of LAD and $C_{\mathrm{d}}$ in the vertical is discussed.

\subsection{Constant LAD}

We assume that both canopy LAD and drag coefficient are constant, expressed by $a_{0}$ and $C_{0}$, respectively. In this case, Eq. 3 becomes,

$$
u(x, z)|u(x, z)|=-P G(x) L_{c}\left[1-\exp \left(a_{0} z\right)\right]+u_{h}^{2}(x) \exp \left(a_{0} z\right)
$$

where $u_{h}(x)$ is the wind velocity at the top of the canopy, i.e., $u(x, 0)$, and $L_{c}=1 /\left(C_{0} a_{0}\right)$ is the canopy adjustment length scale. Above the canopy, we assume that the background wind $\left(U_{\mathrm{B}}\right)$ blows from left to right, namely $U_{\mathrm{B}}>0$. Over a gentle hill, wind perturbations above the canopy top are small compared to $U_{\mathrm{B}}$ as required by the linear solution of JH75 and FB04 (see appendix, Eq. A21) ), which is used as a boundary condition at the canopy top. In this case, there must be a 
layer immediately below the canopy top, in which wind perturbation is still small so that $u$ ( $=U_{\mathrm{B}}$ $+\Delta u)$ remains positive. In such a layer, the solution of wind velocity is,

$$
u(x, z)=\sqrt{-P G(x) L_{c}\left[1-\exp \left(a_{0} z\right)\right]+u_{h}^{2}(x) \exp \left(a_{0} z\right)} .
$$

Equation 4 or 5 suggests that wind speed within the canopy is contributed by two parts. One is related to the topography-induced pressure gradient force. The PG force acts as an accelerating force on the windward side of the hill (i.e., negative $P G$ ), increasing the wind speed. In contrast, the PG force decelerates wind on the leeward side of the hill (i.e., positive $P G$ ), decreasing the wind speed. The decay of wind at the canopy top is caused by drag effects of canopy elements. Deep into the canopy, the first term increases and the second term decreases exponentially. In cases with negative $P G$ values, wind speed is dominated by the PG term and approaches to $\sqrt{-P G(x) L_{c}}$ at sufficiently deep levels within the canopy. In cases with positive $P G$ values, it is feasible that wind speed becomes zero at a level $\left(z_{d}\right)$ when the two terms are equal in magnitude with opposite signs. The level, $z_{d}(<0)$, is determined by

$$
z_{d}(x)=\frac{1}{a_{0}} \ln \left\{\frac{L_{c} P G(x)}{u_{h}^{2}(x)+L_{c} P G(x)}\right\} .
$$

Below $z_{d}(x)$, the sign of $u(x, z)$ becomes negative $(u<0)$. In other words, flow separation occurs and reversed flow can be observed. This appears only on the lee side of the hill, where the PG force is in the opposite direction of the background wind (i.e., $P G>0$ ). If $\left|z_{d}(x)\right|$ is larger than or equal to the canopy depth, the reversed flow cannot be observed.

The height of flow separation $\left(z_{d}\right)$ is determined by three factors: (1) LAD $\left(a_{0}\right),(2)$ wind speed at the top of canopy $\left(u_{\mathrm{h}}\right)$, and (3) the hill-induced pressure gradient. Physically, flow reverses its direction when the momentum penetrated from the canopy top cannot overcome the pressure gradient force with the opposite direction of the flow. The separation height is located 
near the top of the canopy when either the pressure gradient is very strong or wind speed at the top of the canopy is very weak $\left(u_{h}^{2}(x)<<L_{c} P G(x)\right)$. In another extreme case of $u_{h}^{2}(x)>>L_{c} P G(x)$, the separation height is reduced to

$$
z_{d}(x) \approx \frac{1}{a_{0}} \ln \left\{\frac{L_{c} P G(x)}{u_{h}^{2}(x)}\right\} .
$$

LAD plays an important role in determination of the flow separation height. A denser canopy causes the momentum penetrated from the canopy top to decay more rapidly with height deep into the canopy, and hence flow separates at a higher level. FB04 did not show a formula for $z_{d}(x)$, but it can be easily derived. After setting Eq. 30 of FB04 equal to zero, we find that the resulting FB04's separation height formula is the same as Eq. 7, which is a special case of Eq. 6 in our model.

Below the separation level, wind velocity is upslope $(u<0)$ and Eq. 4 becomes,

$$
u(x, z)=-\sqrt{-P G(x) L_{c}\left[1-\exp \left(a_{0} z\right)\right]+u_{h}^{2}(x) \exp \left(a_{0} z\right)} .
$$

With Eq. 6, the above solution can be written as,

$$
u(x, z)=-\sqrt{P G(x) L_{c}\left\{1-\exp \left[a_{0}\left(z-z_{d}\right)\right]\right\}} .
$$

At sufficiently deep levels, wind velocity approaches to $-\sqrt{P G(x) L_{c}}$ and becomes $u_{h^{-}}$ independent.

It is noticed that wind speed values in Eqs. 5 and 9 are not equal to zero on the ground, which is the same as that from FB04 model and is unrealistic. This problem arises from the constant $C_{\mathrm{d}}$ assumption, with which the ground drag effect is not taken into account. This can be improved by imposing large values of $C_{\mathrm{d}}$ at levels close to the ground (see Appendix). 


\subsection{A simple height-dependent LAD distribution}

For some scenarios of $a(z)$, Eq. 3 can be analytically integrated. For example,

$$
a(z)=\frac{1}{b_{0}(z+h)+b_{1}}
$$

where $b_{0}$ and $b_{1}$ are parameters for determining $a(z) . b_{0}$ is restricted i.e. not equal to either 0 or 1 . LAD monotonically increases with height as $b_{0}>0$ and decreases with height as $b_{0}<0$. When wind blows in the same direction as the background wind $(u(x, z)>0)$, the solution of (3) is

$$
u(x, z)=\sqrt{\frac{1}{b_{0}-1} \frac{P G}{C_{d}(z) a(z)}\left(1-\left(\frac{a(z)}{a(0)}\right)^{1-\frac{1}{b_{0}}}\right)+\frac{C_{d}(0) u_{h}^{2}(x)}{C_{d}(z)}\left(\frac{a(z)}{a(0)}\right)^{-\frac{1}{b_{0}}}},
$$

where the continuous boundary condition of $u(x, z)$ at the canopy top has been used.

By letting Eq. 11 equal to zero when $P G>0$, the separation level height, $z_{\mathrm{d}}$, is solved as

$$
z_{d}(x)=\frac{1}{b_{0}}\left\{a(0)^{-\frac{1}{1-b_{0}}}\left[\frac{1}{a(0)}-\frac{\left(b_{0}-1\right) C_{d}(0) u_{h}^{2}(x)}{P G}\right]^{\frac{b_{0}}{b_{0}-1}}-\frac{1}{a(0)}\right\} .
$$

Below $z_{\mathrm{d}}(x)$, wind velocity is upslope and its analytical solution is

$$
u(x, z)=-\sqrt{\frac{1}{b_{0}-1} \frac{P G}{C_{d}(z) a(z)}\left\{\left(\frac{a(z)}{a\left(z_{d}\right)}\right)^{1-\frac{1}{b_{0}}}-1\right\}} .
$$

These analytical solutions Eqs. 11-13 elucidate how canopy structure (different $b_{0}$ and varying LAD) can change flow separation height and wind velocity values, in addition to PG, wind speed at the top of canopy, and drag coefficient, as discussed in Section 2.2. A more detailed discussion on canopy structure effects will be found in Section 3.

\subsection{Arbitrary distributions of LAD and $C_{\mathrm{d}}$}


Although there are no general explicit and analytical solutions to the integrals in Eq. 3 for all types of distributions of LAD and $C_{\mathrm{d}}$, approximate solutions can be found by rewriting Eq. 2 to a difference equation, e.g., using a central difference scheme (e.g., Pielke 2002). Suppose that a canopy layer is divided into $n$ equal segments in the vertical with a spacing of $\Delta z=h / n$, the vertical coordinate of the lowest point of the $m$-th segment is $z(m)=-m \Delta z$, where $m=1$ to $n$. With some algebraic rearrangements of the difference equation, we have,

$$
\begin{aligned}
u^{2}(x,-m \Delta z)= & \frac{C_{d}(0) u_{h}^{2}(x)}{C_{d}(-m \Delta z)} \prod_{k=-m+1}^{0} \frac{1-\beta(k)}{1+\beta(k)}- \\
& \frac{P G \Delta z}{C_{d}(-m \Delta z)}\left\{\sum_{k=-m+1}^{0}\left[\frac{1}{1+\beta(k+1)}\left(\prod_{j=-m+1}^{k} \frac{1-\beta(j)}{1+\beta(j)}\right)\right]+\frac{1}{1+\beta(m+1)}\right\}
\end{aligned}
$$

where $\beta(k)=0.5(a(k \Delta z)+a((k-1) \Delta z)) \Delta z$. As discussed in Sections 2.2 and 2.3, the first term on the right-hand side (RHS) of Eq. 14 represents the decay of wind speed at the top of canopy, while the second term represents the contribution of the topography-induced pressure gradient forcing. In cases with a negative PG, it is impossible for the RHS of Eq. 14 to reach zero above the ground. That is to say, flow separation does not occur with a negative PG. In contrast, a positive PG can cause wind direction changes to the PG force direction as wind decays sufficiently deep into the canopy. Given a constant positive PG, the separation height depends on how rapidly the wind from above the canopy decays with height downward into the canopy. For a given $x$, one can calculate wind speed starting from $m=1$ with an increment of 1 . The first level (say $z(q)=-q \Delta z$ ), where the RHS of Eq. 14 becomes negative or zero, can be approximated as the flow separation level, i.e., $z_{\mathrm{d}}=z(q)$. Above $\left|z_{\mathrm{d}}\right|$, wind velocity is equal to the square root of Eq. 14. Below $z_{d}$, wind velocity is given by,

$$
u(x,-m \Delta z)=-\sqrt{\frac{P G \Delta z}{C_{d}(-m \Delta z)}\left\{\sum_{k=-m+1-q}^{-q}\left[\frac{1}{1+\beta(k+1)}\left(\prod_{j=-m+1-q}^{k} \frac{1-\beta(j)}{1+\beta(j)}\right)\right]+\frac{1}{1+\beta(m+1)}\right\}} .
$$




\section{Applications}

To demonstrate the advantages of the present model over FB04 model, six experiments were performed (Table 2). Suppose that a gentle hill of a sinusoidal shape (Fig. 1b) as defined by Eq. A13, with the hill half-length, $L_{\mathrm{h}}=100 \mathrm{~m}$, and hill height, $H=10 \mathrm{~m}$, is covered by a dense canopy. For all experiments, $u *$ is taken as $1 \mathrm{~m} \mathrm{~s}^{-1}$. LAD is assumed to be vertically uniform in the first experiment (hereafter E1, where 'E' stands for 'experiment') in order to compare the results from the present model with those from FB04 model. This is because FB04 model can only handle the scenarios with vertically-uniform LAD distributions (i.e. constant LAD). In E2 and E3, two idealized vertical distributions of LAD are assumed for illustrating the effects of vertically-varied LAD on wind fields. In E4, the vertical distributions of LAD and $C_{\mathrm{d}}$, derived from observations, are used. E5 and E6 are designed to isolate the effects of the vertical variations in $\mathrm{LAD}$ and $C_{\mathrm{d}}$ on canopy wind profiles.

\subsection{Constant LAD}

In E1, we assume $h=10 \mathrm{~m}, C_{\mathrm{d}}=0.2$, and $\mathrm{LAD}=0.4 \mathrm{~m}^{2} \mathrm{~m}^{-3}$. Using the formulas in the Appendix, we first calculate the canopy adjustment length scale $\left(L_{\mathrm{c}}=12.5 \mathrm{~m}\right)$, displacement height $(d=5.59 \mathrm{~m})$, canopy roughness length $\left(z_{0}=2.28 \mathrm{~m}\right)$, inner region height $\left(h_{\mathrm{i}}=16 \mathrm{~m}\right)$, middle layer height $\left(h_{\mathrm{m}}=56 \mathrm{~m}\right)$, and characteristic wind in the outer region $\left(U_{0}=8 \mathrm{~m} \mathrm{~s}^{-1}\right)$. Then the background wind is calculated with Eq. A8 and wind speed at canopy top is calculated with Eqs. A21 and A26. Finally, wind profiles within the canopy at different horizontal locations $(x)$ are calculated with Eqs. 5 and 8. 
The streamline pattern simulated from the present model is overall similar to that from FB04 model in terms of the recirculation region and separation height on the lee side as well as horizontal variations of hill-induced wind perturbations (Figures omitted). Differences of canopy flow simulated from the two models are highlighted in Fig. 2. Fig. 2a shows that the vertical profiles of wind velocity within the canopy at seven locations $(x)$ derived from the two models are in good agreement in the upper layer but not in the lower layer near the ground. The wind profile pattern predicted by our model is $S$-shaped on the windward side and $C$-shaped on the leeward side; this feature is not revealed by FB04 model since wind speed in the lower part of the canopy predicted by their model is almost constant. The reason is because the no-slip boundary condition can be applied to the nonlinear differential equation in our model but it is not able to be applied to the nonlinear algebraic equation in the FB04 model. Fig. 2b compares the profiles of kinematic stress from our model and from the FB04 model. The two predictions are in excellent agreement with each other at locations D (crest), A and G (trough). The kinematic stress predicted by the present model is larger than that predicted by the FB04 model on the slope of the windward side and smaller on the slope of the leeward side. The kinematic stress predicted by the FB04 model is always zero in the lower part of the canopy due to the constant wind speed predicted by the nonlinear algebraic equation in the FB04 model. The stress predictions from our model are more rational because the predicted positive stress on the windward side indicates momentum absorption, while the predicted negative stress on the leeward side in the recirculation region $(u<0)$ indicates that momentum flux changes its orientation as wind changes its direction. In particular, the stress predicted by the FB04 model in the vicinity of $z=-4 \mathrm{~m}$ level on locations $\mathrm{E}$ and $\mathrm{F}$ becomes unreasonably large (Fig. 2b). 


\subsection{Idealized distributions of height-dependent LAD}

The second and third experiments (E2 and E3) are the same as E1 except that LAD varies with height. Given that LAI is the same as that in E1, the values of $b_{0}$ and $b_{1}$ in Eq. 10 are taken as -0.2 and $3.63 \mathrm{~m}$ in $\mathrm{E} 2$, respectively, representing a LAD distribution that increases with height from the ground to the canopy top (dotted line in Fig. 3a). Similarly, $b_{0}$ and $b_{1}$ are taken as 0.2 and $1.63 \mathrm{~m}$ in $\mathrm{E} 3$, respectively, representing a LAD distribution that decreases with height (dashed line in Fig. 3a). Different LAD distributions result in different values of $d, z_{0}, h_{m}$, and $U_{0}$ (Table 2). For the given $u_{*}\left(=1 \mathrm{~m} \mathrm{~s}^{-1}\right)$, the mean wind profiles are different among E1, E2, and E3 (Fig. 3b). Above the canopy, wind speed in E2 is the largest due to the largest LAD in the upper canopy. Larger LAD values in the upper canopy causes less momentum penetrating into the canopy, resulting in the larger wind speed above the canopy. Within the canopy, wind speed in E2 decreases downward with height more rapidly in the upper canopy than that in E3 due to larger LAD, while it decreases more slowly in the lower canopy due to smaller LAD. In addition, the magnitude of the topography-induced PG in E2 is the largest due to the largest $U_{0}$ (Table 2 and Eq. A18).

Over the hill, the vertical profiles of wind velocity are similar in shape but different in magnitude among E1, E2, and E3 (Fig. 4). Above the canopy, differences in the wind profiles are similar to those in the background wind profiles (Fig. 3b), except that they vary with location due to the horizontally-varied PG. Within the canopy, differences in wind profiles are small on the upwind side. The most apparent difference among the three experiments lies in the separation height on the lee side, which can be explained by the following two aspects. Firstly, varying LAD directly alters the drag force term and hence the momentum balance. A larger LAD results in wind speed decreasing more rapidly with height downward into the canopy; this is favorable 
for canopy flow to separate at a higher level (e.g. E2 versus E3). Secondly, varying LAD may change the background wind and, therefore, indirectly affect the magnitude of the PG force through $U_{0}$ according to Eq. A18 (Table 2). On the lee side where the PG force is in the opposite direction of wind, a stronger PG force decelerates flow more strongly and can cause the wind speed to reach zero at a higher level. In E2, both the PG force and LAD in the upper canopy are the largest in magnitude. As a result, wind speed on the lee side can reach zero at the highest level (Fig. 5).

\subsection{Varying LAD and $C_{\mathrm{d}}$}

In E4, we use LAD and $C_{\mathrm{d}}$ derived from observations (Fig. 6) for the canopy ( $h=15 \mathrm{~m}$ ) at the Niwot Ridge AmeriFlux site (Yi et al. 2005) as an example to show how the heightdependent distributions of $C_{\mathrm{d}}$ and LAD affect wind profiles. LAD and $C_{\mathrm{d}}$ values at a given level are estimated by linearly interpolating available data at nearby points except that $C_{\mathrm{d}}$ near the ground is estimated by the logarithm function of the distance from the ground as described in the Appendix. For further comparison, we conduct two more experiments (E5 and E6). In E5, LAD is imposed to be uniformly distributed in the vertical and is equal to the average of the varying LAD values used in $\mathrm{E} 4$, while, in $\mathrm{E} 6$, both $C_{\mathrm{d}}$ and $\mathrm{LAD}$ are imposed to be uniformly distributed in the vertical and equal to the averages of the varying $C_{\mathrm{d}}$ and $\mathrm{LAD}$ values ${ }^{1}$, respectively. Significant differences in $z_{0}$ and $d$ are found among the three experiments (Table 2). Parameters $d$ and $z_{0}$ are determined by LAD, $C_{\mathrm{d}}$, and the gradient of $C_{\mathrm{d}}$ at the canopy top (see Eqs. A11 and A12). Comparing E4 with E5 where both $\mathrm{C}_{\mathrm{d}}$ distributions are identical, we find that using the height-dependent LAD results in differences in $d$ and $z_{0}$ by a factor of about 2. Comparing E5 with E6 where both LAD distributions are identical, we find that using the height-dependent $C_{\mathrm{d}}$

\footnotetext{
${ }^{1}$ Treatment of $\mathrm{C}_{\mathrm{d}}$ near the ground in E6 remains the same as that in E4.
} 
results in differences in $d$ by a factor of 3 and $z_{0}$ by a factor of 10. Fig. 7 shows the vertical profiles of the background wind velocities from the three experiments. The shape of the wind profile within the canopy is significantly affected by the vertical distributions of LAD and $C_{\mathrm{d}}$. The wind profiles with the height-dependent $C_{\mathrm{d}}$ are more like the ' $\mathrm{S}$ ' shape than those with the constant $C_{\mathrm{d}}$. With the constant LAD and $C_{\mathrm{d}}$, wind speed monotonically decreases with height downward into the canopy while it can increase or remain with little variation for the scenario with the height-dependent distributions of LAD and $C_{\mathrm{d}}$. In addition, the characteristic wind speed $\left(U_{0}\right)$ values in the outer region are equal to 12,13 , and $8 \mathrm{~m} \mathrm{~s}^{-1}$ for $\mathrm{E} 4$, E5, and E6, respectively. As a result, the topography-induced PG values differ in magnitude, with the minimum in E6 and maximum in E5.

Over the hill, wind speed differences above the canopy among the three experiments vary with location, with the largest appearing in the hill crest and smallest in the trough (Fig. 8). Within the canopy, the wind profiles are different in shape and in magnitude (wind speed) at locations $\mathrm{B}$ and $\mathrm{C}$ on the upwind side and at locations $\mathrm{E}$ and $\mathrm{F}$ on the lee side of the hill.

On the upwind side of the hill, apparent $S$-shaped wind velocity profiles are predicted within the canopy at $\mathrm{B}$ and $\mathrm{C}$ for the scenario with the height-dependent distributions of LAD and $C_{\mathrm{d}}$ (i.e., E4). Near the ground, wind speed is small due to the strong drag effect exerted by the ground, and increases with height as the ground drag effect decreases. On the lower and middle levels of the canopy, the canopy drag force is mainly balanced by the topographyinduced PG force. In this case, a smaller LAD or $C_{\mathrm{d}}$ results in a larger wind speed (for a given PG). This can explain why wind speed values in the lower levels are larger than those in the middle levels (because LAD and $C_{\mathrm{d}}$ increase with height approximately below the level of $z=-8 \mathrm{~m}$ (Fig. 6) ). In the upper canopy, wind speed increases with height both due to the 
decreasing of $C_{\mathrm{d}}$ and $\mathrm{LAD}$ and due to the increasing of momentum penetrated from the canopy top. For the scenario with the height-dependent $C_{\mathrm{d}}$ but constant LAD (i.e., E5), the shape of the wind profile is similar to that in E4, despite slight differences in wind speed due to different LAD distributions. For the scenario with constant $C_{\mathrm{d}}$ and $\mathrm{LAD}$ (i.e., E6), the variation in wind velocity with height is smallest among the three experiments. Wind speed in E6 keeps decreasing or nearly invariant with height and, therefore, the shape of the wind profile is least like the ' $S$ ' shape; this suggests that the vertical variation of $C_{\mathrm{d}}$, dependent on the distribution of LAD, plays an important role in simulating the shape of wind profiles within the canopy.

On the lee side of the hill, the $C$-shaped wind profile pattern appears in all three experiments. Main differences among them lie in two aspects. Firstly, the flow predicted in E4 separates at a deeper level than that in E5. This can be explained by the direct and indirect effects of different LAD distributions as discussed in Section 3.2. For E5 and E6 with different $C_{\mathrm{d}}$ distributions but same LAD distributions, the flow separation level in E5 is higher than that in E6 mainly due to the more negative PG forcing in E5 (i.e., the indirect effect of $C_{\mathrm{d}}$, similar to the explanation in Section 3.2 for $\mathrm{LAD}$ ) causing the wind speed to reach zero at a shallower level. Secondly, the variations in wind speed with height below the separation level are different. Similar to those on the upwind side of the hill, wind speed can increase downwards at the lower part of canopy layer for the height-dependent $C_{\mathrm{d}}$ scenarios (E4 and E5), while such an increase is not apparent for the constant $C_{\mathrm{d}}$ scenario (E6).

\section{Discussion}

This section examines the vertical and horizontal advection terms in the streamwise momentum equation. As an example, analyses at $x=0$ are made, where PG is equal to zero for 
the prescribed hill according to Eq. A18. Within the canopy, the vertical gradient of the turbulent stress term is,

$$
\frac{\partial \tau}{\partial z}=\frac{u_{h}^{2}}{L_{c}} \exp \left(a_{0} z\right)
$$

and the horizontal advection term is,

$$
u \frac{\partial u}{\partial x}=-\frac{1}{2} \frac{\partial P G}{\partial x} L_{c}\left[1-\exp \left(a_{0} z\right)\right]+\frac{1}{2} \frac{\partial u_{h}^{2}}{\partial x} \exp \left(a_{0} z\right)
$$

Near the canopy top $(z \sim 0)$, Eq. 17 is dominated by the second term on RHS because $\exp \left(a_{0} z\right)$ is close to 1 . In this case, the magnitude of the horizontal advection term is small compared to that of the vertical gradient of the turbulent stress if $L_{c} \ll L_{\mathrm{h}}$. Deep into the canopy $(z<0)$, the magnitude of the stress gradient decreases exponentially (see Eq.16), while the magnitude of the first term on RHS of Eq. 17 increases. To find the level $\left(z_{c}\right)$ where both Eq. 16 and Eq. 17 have the same magnitude, we equate Eq. 16 to the first term on RHS of Eq. 17, and have

$$
z_{c}=-\frac{1}{a_{0}} \ln \left[1+\left(\frac{32}{\pi^{3}}\right)\left(\frac{u_{h}^{3}}{U_{0}^{2}}\right)\left(\frac{L^{3}}{H L_{c}^{2}}\right)\right]
$$

That is to say, the horizontal advection term can be neglected only for levels far above $\left|z_{\mathrm{c}}\right|$.

Based on the continuity equation, the vertical velocity at a given $z(<0$, within the canopy) is given by $w(x, z)=-\int_{-h}^{z} \frac{\partial u\left(x, z^{\prime}\right)}{\partial x} d z^{\prime}$. With some algebra, the vertical advection term can be written as,

$$
\begin{aligned}
w \frac{\partial u}{\partial z}= & \frac{L_{c}}{2} \frac{\partial P G}{\partial x}\left[\exp \left(\frac{a_{0} h}{2}\right)-\exp \left(-\frac{a_{0} z}{2}\right)\right] \exp \left(\frac{a_{0} z}{2}\right) \\
& +u_{h} \frac{\partial u_{h}}{\partial x}\left[\exp \left(\frac{a_{0} z}{2}\right)-\exp \left(-\frac{a_{0} h}{2}\right)\right] \exp \left(\frac{a_{0} z}{2}\right)
\end{aligned}
$$


The second term on RHS of Eq. 19 is smaller than Eq. 16 in magnitude if $L_{h} \gg>L_{\mathrm{c}}$. Comparing the first term on RHS of Eq. 19 with Eq. 16, the following relation needs to be satisfied so that the vertical advection term is smaller than the stress gradient term in magnitude,

$$
z>\frac{2}{a_{0}} \ln \left[\frac{\pi^{3}}{32}\left(\frac{U_{0}^{2}}{u_{h}^{2}}\right)\left(\frac{H L_{c}}{L^{3}}\right)\left(\exp \left(\frac{a_{0} h}{2}\right)-1\right)\right] .
$$

Let $z=-h$, we can find an approximate value of the maximum canopy depth $\left(h_{c m}\right)$ so that the vertical advection term can be smaller than the stress gradient term in magnitude throughout the canopy layer,

$$
h_{c m} \approx \frac{1}{a_{0}} \ln \left[\frac{32}{\pi^{3}}\left(\frac{u_{h}^{2}}{U_{0}^{2}}\right)\left(\frac{L^{3}}{H L_{c}^{2}}\right)+1\right],
$$

Eqs. 18 and 21 are consistent and suggest that advection might be important for tall canopies.

\section{Summary}

A nonlinear canopy flow model is proposed to solve wind profiles within a dense canopy over a gentle hill. Major assumptions made in this study include: (1) terrain slope is gentle $\left(H<<L_{\mathrm{h}}\right)$, and the canopy adjustment length scale is small compared to $L_{\mathrm{h}}$; (2) topographyinduced pressure perturbation is in opposite phase with the hill surface, and remains invariant through the inner boundary layer at a given location; and (3) the advection terms are neglected in the momentum equation within the canopy but remained above the canopy.

Compared with the FB04 model, more features of in-canopy flows over a gentle hill can be analytically derived from the new model. Major advantages are summarized below.

(i) A consistent physical model Canopy flow over a gentle forested hill is described by a single nonlinear differential equation with the balance of three forces: canopy drag, topography-induced pressure gradient and turbulent stress gradient. This nonlinear differential 
equation is closed by the velocity-square law as a parameterization scheme. The physical inconsistency generated by using the mixing-length theory in the FB04 model, i.e., a constant mixing-length assumption leading to a varying mixing-length prediction, is avoided. The effect of surface drag can be taken into account by a no-slip boundary layer condition in our model. Thus, our model prediction of S-shaped wind profiles on the windward side and $C$-shaped wind profiles on the leeward side (Fig. 8) is more realistic and close to observations from laboratory experiments (Poggi et al. 2008). The nonlinear algebraic equation for momentum transfer in the lower part of canopy used in FB04 model is height-independent, actually serving as a bottom boundary condition for the linear differential momentum equation in the upper canopy layer. The predicting ability of FB04 model is largely restricted by using the height-independent algebraic equation in the bottom canopy layer.

(ii) Flow separation height The dependence of the flow separation height on LAD, wind speed at top of canopy, and the perturbation pressure gradient is predicted by the present nonlinear model. The separation height is a result of the competition between $u_{h}^{2}$ and $L_{c} P G$. The separation level is closer to the top of canopy with a stronger $L_{c} P G$. The separation height formula derived from the FB04 model is a special case $\left(L_{c} P G \gg u_{h}^{2}\right)$ of our model predictions.

(iii) Effects of height-dependent LAD and $\boldsymbol{C}_{\mathbf{d}}$ The present nonlinear model can handle the scenarios of height-dependent LAD and $C_{\mathrm{d}}$ distributions, while FB04 model cannot. Our model elucidates that varying $\mathrm{LAD}$ and $\mathrm{C}_{\mathrm{d}}$ in the vertical; affect canopy flows in terms of magnitude and distribution of wind velocity as well as flow separation height through directly altering the drag effect and the canopy flow momentum balance. Varying LAD and $C_{\mathrm{d}}$ also have a large impact on the background wind distribution (Fig. 7), particularly on the characteristic wind velocity $\left(U_{0}\right)$ in the outer region. Because the perturbation pressure gradient in the inner 
region is formulated as a function of $U_{0}$, canopy flow momentum balance can be altered indirectly by varying $\mathrm{LAD}$ and $C_{d}$.

This study has demonstrated the advantages of using the velocity-squared law as a closure scheme for canopy momentum transfer in forested hills over using the mixing-length theory in FB04 model. The success of using the velocity-squared law as a closure in enhancing predicting ability of canopy flows, keeping theory consistent and simple, has great promise to extend the current model to arbitrary terrain. This canopy model can be applied to parameterizing drag effects and dispersion of scalars due to complex flow induced by canopies on sub-grid scales in large scale models, replacing the commonly-used canopy roughnessparameterization in most models.

Acknowledgements:

This work was financially supported by the National Science Foundation under Grant No. ATM-0930015. The first author is supported by the National Natural Science Foundation of China under Grant No. 41075039. The authors thank Drs. Ian Harman and John Finnigan from CSIRO for help with the calculation of wind field using the FB04 model. The authors also thank Christine Ramadhin for valuable comments on the manuscript.

\section{Appendix}

\section{Wind over a flat forested surface}

Over a flat forested surface, the turbulent stress in the layer above the canopy (Fig 1a) is governed (Sutton 1953; Wyngaard 1973; Yi 2008) by

$$
\frac{\partial \tau_{B}}{\partial z} \approx 0
$$


where $\tau_{B}=-\overline{u^{\prime} w^{\prime}}$ and is the kinematic turbulent stress, $u^{\prime}$ and $w^{\prime}$ are the fluctuations of velocity components in the horizontal and vertical, respectively. The mixing-length model, in which

$$
\tau_{B}(z)=\left(\kappa(z+d) \frac{\partial U_{B}}{\partial z}\right)^{2}
$$

is valid in this layer, where $d$ is the displacement height associated with the canopy and the origin of the vertical coordinate is taken at the canopy top. Based on (A2), the mean velocity profile, $U_{B}$, can be derived from (A1), i.e,

$$
U_{B}(z)=\frac{u_{*}}{\kappa} \ln \left(\frac{z+d}{z_{0}}\right),
$$

where $z_{0}$ is the roughness length of the canopy, $u_{*}$ is the friction velocity.

Within the canopy layer (Fig 1a, $z=-h$ to 0 , where $h$ is the canopy depth), according to the hypothesis in Yi (2008), the governing equation of the kinematic turbulent stress for a dense canopy can be given by

$$
\frac{\partial \tau_{B}(z)}{\partial z}=F_{d} \approx a(z) \tau_{B}(z)
$$

where $a(z)$ is LAD and $\mathrm{F}_{\mathrm{d}}$ is the drag forcing exerted by the canopy. In Eq. A4, we have assumed that the drag on flow with a dense canopy is attributed largely to canopy elements except near the ground, i.e.,

$$
\tau_{B}(z)=C_{d}(z) U_{B}^{2}(z)
$$

where $C_{d}(z)$ is a bulk drag coefficient and is a function of height and canopy morphology. The analytical solution of the kinematic turbulent stress derived from Eq. A4 is

$$
\tau_{B}(z)=\tau_{B}(0) e^{-(L A I-L(z))}
$$


where $\tau_{B}(0)=-\overline{u^{\prime} w^{\prime}}(0)=u_{*}^{2}$ is the kinematic turbulent stress at the canopy top, LAI is the leaf area index, and

$$
L(z)=\int_{-h}^{z} a\left(z^{\prime}\right) d z^{\prime}
$$

is the cumulative leaf area per unit ground area below height $z$. Equation A6 indicates that the turbulent stress can be predicted by LAD profile alone, which is in excellent agreement with observations (Yi, 2008).

The mean wind profile within the canopy can be derived from Eqs. A5 and A6 as

$$
U_{B}(z)=U_{h}\left(\frac{C_{d}(0)}{C_{d}(z)}\right)^{\frac{1}{2}} e^{-\frac{1}{2}(L A I-L(z))},
$$

where $U_{h}$ is the wind speed at the top of canopy.

Assuming that mean wind velocity and shear stress are continuous at the canopy top $(z=0)$, i.e., wind speed and its derivative with respect to $z$ from (A8) at the canopy top are equal to those from (A3), and the shear stress from (A6) at $z=0$ is equal to that from (A2), we have

$$
\begin{aligned}
& u_{*}^{2}=C_{d}(0) U_{h}^{2}, \\
& U_{h}=\frac{u_{*}}{\kappa} \ln \left(\frac{d}{z_{0}}\right), \\
& d=\frac{2 \sqrt{C_{d}(0)}}{\kappa\left[-\frac{1}{C_{d}(0)} \frac{\partial C_{d}(0)}{\partial z}+a(0)\right]}, \\
& z_{0}=d \exp \left(-\frac{\kappa}{\sqrt{C_{d}(0)}}\right)
\end{aligned}
$$

If both $a(z)$ and $C_{\mathrm{d}}(z)$ are constant, Eqs. A11 and $\mathrm{A} 12$ are reduced to those in Eq. 6 of FB04. 


\section{Wind above the canopy over a gentle hill}

As in FB04, the shape of a sinusoidal hill (Fig. 1b) is described in the rectangular coordinate system $(X, Z)$ as

$$
Z_{s}=\frac{1}{2} H \cos (k X)-h
$$

where $Z_{s}$ is the surface height; $H$ is the hill height; $k$ is equal to $\pi /\left(2 L_{h}\right) ; L_{h}$ is the hill half-length.

To obtain an analytical solution, two assumptions about the prescribed hill are made.

First, the hill slope is sufficiently low, and perturbations to the background wind $\left(U_{\mathrm{B}}\right)$ above the canopy can be solved with linearized equations. Second, the hill is long enough. This means that $L_{h}$ should be greater than $2 L_{\mathrm{c}}$ (Poggi et al. 2008), where $L_{\mathrm{c}}$ is a canopy adjustment length scale which is equal to $1 /\left(C_{d 0} a_{0}\right), C_{\mathrm{d} 0}$ and $a_{0}$ are the characteristic values for the canopy drag coefficient and LAD, respectively. In this case, the advection terms in the momentum equation may be negligible for a dense canopy over gentle terrain. This assumption has been supported by numerical experiments (Ross and Vosper 2005).

The same displaced coordinate system as in FB04 is used. The displaced $(x, z)$ and the rectangular $(X, Z)$ coordinate systems are related by,

$$
\begin{aligned}
& x=X+\frac{H}{2} \sin (k X) e^{-k Z}, \\
& z=Z-\frac{H}{2} \cos (k X) e^{-k Z} .
\end{aligned}
$$

with this displaced (streamline) coordinate system, extra terms appear in the momentum equations (compared with those in a rectangular coordinate system), which are $O\left(H^{2} / L_{h}^{2}\right)$ or smaller and, hence, may be negligible for the low slope hill (see FB04 for details). As a result, the streamwise ( $x$-direction) momentum equation can be written as, 


$$
u \frac{\partial u}{\partial x}+w \frac{\partial u}{\partial z}=-\frac{\partial p}{\partial x}+\frac{\partial \tau}{\partial z}
$$

where $u$ and $w$ are the wind components in the $x$ and $z$ directions; receptively, $p$ is the kinematic pressure, $\tau$ is the kinematic turbulent shear stress above the canopy, which is parameterized using the mixing-length theory.

Under neutral conditions, the pressure perturbation in the inner region induced by the gentle sinusoidal hill is represented by

$$
\Delta p(x)=-\frac{1}{2} U_{0}^{2} H k \exp (i k x)
$$

(Jackson and Hunt 1975; Finnigan and Belcher 2004) and the horizontal pressure gradient (PG) forcing, driving the flow throughout the depth of the inner region (and canopy), is

$$
P G=\operatorname{Re}\left(\frac{\partial \Delta p}{\partial x}\right)=\frac{1}{2} U_{0}^{2} H k^{2} \sin (k x),
$$

where $U_{0}$ is the characteristic wind velocity in the outer region and is estimated as the background wind at the middle layer height $h_{m}$. According to Hunt et al. (1988), $h_{m}$ is given by,

$$
\frac{h_{m}}{L_{h}}\left(\ln \left(h_{m} / z_{0}\right)\right)^{1 / 2}=1
$$

provided that $L_{h}$ is less than the boundary layer depth. The height of the inner region, $h_{i}$, is defined by,

$$
\frac{h_{i}}{L_{h}} \ln \left(h_{i} / z_{0}\right)=2 \kappa^{2}
$$

Assuming that the wind perturbation induced by terrain is small compared to the background wind (i.e., wind over the corresponding flat surface), Eq. A16 can be linearized. The resulting approximate solution for the streamwise velocity in the inner region above the canopy is, 


$$
u(x, z)=U_{B}(z)+\Delta u(x, z)
$$

where

$$
\Delta u(x, z)=\operatorname{Re}\left\{-\frac{\Delta p(x)}{U_{B}\left(h_{i}\right)}\left[1+\delta\left(1-\ln \left(\frac{z+d}{h_{i}}\right)-c K_{0}\left(2 \sqrt{i k L_{h} \frac{z+d}{h_{i}}}\right)\right]\right\}\right.
$$

$\delta=1 / \ln \left(h_{i} / z_{0}\right)$, and $K_{0}$ is the modified Bessel function of order zero.

The turbulent stress is,

$$
\tau(x, z)=\tau_{B}(z)+\Delta \tau(x, z)
$$

where

$$
\Delta \tau(x, z)=2 \kappa u_{*}(z+d) \frac{\partial \Delta u(x, z)}{\partial z}
$$

The integration constant $c$ is determined by coupling (A21) and (A23) to the solutions for flow within the canopy at $z=0$ (canopy top). Assuming that turbulent stress and velocity are continuous at $z=0$, respectively, we have,

$$
C_{d}(0)\left[U_{B}(0)+\Delta u(x, 0)\right]^{2}=\tau_{B}(0)+\Delta \tau(x, 0) .
$$

It is noticed that the exact value of constant $c$ (that should be independent of position $x$ and $z$ ) may not be achieved because the wind speed perturbation above the canopy is linear in PG (a function of $x$ ) while it is nonlinear within the canopy. This is due to different simplifications of the governing equation above and within the canopy. An approximate solution is provided here. Since the velocity perturbation is small compared with $U_{\mathrm{B}}$, the left side of the above equation can be approximated as $C_{d}(0)\left[U_{B}{ }^{2}(0)+2 U_{B}(0) \Delta u(x, 0)\right]$. Substituting (A2), (A3), (A22), (A24) into (A25), we have,

$$
c=\frac{-C_{d}(0) U_{B}(0) U_{B}\left(h_{i}\right)\left[1+\ln \left(h_{i} / z_{0}\right)-\ln \left(d / h_{i}\right)\right]-u_{*}^{2} \ln \left(h_{i} / z_{0}\right)}{u_{*}^{2} d\left(\partial K_{0}(g) / \partial z\right) \ln \left(h_{i} / z_{0}\right)-C_{d}(0) U_{B}(0) U_{B}\left(h_{i}\right) K_{0}(g)},
$$


where $g=2 \sqrt{i k L_{h} \frac{z+d}{h_{i}}}$. With the above approximate value of $c$, the resulting vertical profiles of wind and turbulent stress are approximately continuous but may not be smooth at the canopy top in some locations (i.e., their first derivatives with respect to $z$ are not continuous at $z=0$ ).

\section{3. $C_{\mathrm{d}}$ near the ground}

For the no-canopy case under a neutrally stratified atmosphere, the drag coefficient is given by

$$
C_{d}(z)=\left[\frac{\kappa}{\ln \left(z / z_{g 0}\right)}\right]^{2}
$$

where $z_{\mathrm{g} 0}$ is the roughness length of the ground. Equation A27 indicates that $C_{d}$ is infinite on the ground, and decreases dramatically with height near the ground. Variations in $C_{d}$ are smaller at higher levels. For example, variation in $C_{\mathrm{d}}$ is smaller than 0.03 for $z$ between $10 z_{\mathrm{g} 0}$ and $10^{3} z_{\mathrm{g} 0}$. To account for significant variations in $C_{d}$ near the ground where the drag effect exerted by the ground is superior to that by canopy, we assume that $C_{d}$ follows (A27) below a level $z_{L}$. Thus, we can rewrite $(\mathrm{A} 27)$ as

$$
C_{d}(z)=C_{d}\left(z_{L}\right)\left(\frac{\ln \left(z_{L} / z_{g 0}\right)}{\ln \left(z / z_{g 0}\right)}\right)^{2}
$$

where $C_{d}\left(z_{L}\right)$ is the drag coefficient at $z_{L}$ and $z_{\mathrm{g} 0}$ is taken to be $0.1 \mathrm{~m}$ in the study. 
References:

Albini, F. A. (1981), A phenomenological model for wind speed and shear stress profiles in vegetation cover layers. J. Appl. Meteorol., 20, 1325-1335.

Allen, T. and A. R. Brown (2002), Large-eddy simulation of turbulent separated flow over rough hills. Boundary-Layer Meteorol., 102, 177-198.

Amiro, B. D. (1990), Comparison of turbulence statistics within three boreal forest canopies. Boundary-Layer Meteorol., 51, 99-121.

Aubinet M, B. Heinesch, and M. Yernaux (2003), Horizontal and vertical CO2 advection in a sloping forest. Boundary-Layer Meteorol., 108, 397-417.

Baldocchi, D. D., and T. P. Meyers (1988), Turbulence structure in a deciduous forest. Boundary-Layer Meteorol., 43, 345-364.

Barr, S. (1971), A modeling study of several aspects of canopy flow. Mon. Wea. Rev., 99, 485493.

Belcher, S. E. and J. C. R. Hunt (1998), Turbulent flow over hills and waves. Annu. Rev. Fluid Mech., 30, 507-538.

Belcher, S. E., T. M. J. Newley, and J. C. R. Hunt (1993), The drag on an undulating surface induced by the flow of a turbulent boundary layer. J. Fluid Mech., 249, 557-596.

Bergen, J. D. (1971), Vertical profiles of windspeed in a pine stand. For. Sci., 17, 314-322.

Bradley, E. F. (1980), An experimental study of the profiles of wind speed, shearing stress and turbulent intensities at the crest of a large hill. Quart. J. Roy. Meteorol. Soc., 106, 101124. 
Brown, A. R., J. M. Hobson, and N. Wood (2001), Large-eddy simulation of neutral turbulent flow over rough sinusoidal ridges. Boundary-Layer Meteor., 98, 411-441.

Burns, S.P., J. Sun, D.H. Lenschow, S.P. Oncley, B.B. Stephens, C. Yi, D.E. Anderson, J. Hu, and R.K. Monson (2011), Atmospheric stability effects on wind fields and scalar mixing within and just above a subalpine forest in sloping terrain. Boundary-Layer Meteorology, 138, 231-262, doi:10.1007/s10546-010-9560-6.

Cionco, R. M. (1965), A mathematical model for air flow in a vegetative canopy. J. Appl. Meteorol., 4, 517-522.

Cionco, R. M. (1972), A wind-profile index for canopy flow. Boundary-Layer Meteorol., 3, 255263.

Coceal, O., T. G. Thomas, I. P. Castro, and S. E. Belcher (2006), Mean flow and turbulence statistics over groups of urban-like cubical obstacles, Boundary-Layer Meteorol., 121, $491-519$

Dupont, S., Y. Brunet, and J. J. Finnigan (2008), Large-eddy simulation of turbulent flow over a forested hill: Validation and coherent structure identification. Quart. J. Roy. Meteorol. Soc., 134, 1911-1929.

Dwyer, M. J., E. G. Patton, and R. H. Shaw (1997), Turbulent kinetic energy budgets from a large-eddy simulation of airflow above and within a forest canopy. Boundary-Layer Meteorol., 84, 23-43.

Edburg,S.L., G. Allwine, B. Lamb, D. Stock, H. Thistle, H. Peterson, B. Strom (2010), A simple model to predict scalar dispersion within a successively thinned loblolly pine canopy, $J$. Appl. Meteorol \& Climate, doi: 10.1175/2010JAMC2339.1, 49, 1913-1926. 
Feigenwinter, C., C. Bernhofer, and R. Vogt (2004), The influence of advection on the short term $\mathrm{CO}_{2}$-budget in and above a forest canopy. Boundary-Layer Meteorol., 113, 201-224

Feigenwinter, C., C. Bernhofer, U. Eichelmann, B. Heinesch, M. Hertel, D. Janous, O. Kolle, F. Lagergren, A. Lindroth, S. Minerbi, U. Moderow, M. Molder, L. Montagnani, R. Queck, C. Rebmann, P. Vestin, M. Yernaux, M. Zeri, W. Ziegler, and M. Aubinet (2008), Comparison of horizontal and vertical advective $\mathrm{CO}_{2}$ fluxes at three forest sites. Agr. For. Meteorol., 148, 12-24.

Finnigan, J. J. and S. E. Belcher (2004), Flow over a hill covered with a plant canopy. Quart. J. Roy. Meteorol. Soc., 130, 1-29.

Finnigan, J. J. (2008), An introduction to flux measurements in difficult conditions. Ecol. Appl., $18,1340-1350$.

Fischenich, J. C. (1996), Velocity and resistance in densely vegetated floodways. Ph.D. thesis, Colorado State University, 203 pp.

Fons, R. G. (1940), Influence of forest cover on wind velocity. J. For., 38, 481-486.

Goulden, M. L., J. W. Munger, S. M. Fan, B. C. Daube, and S. C. Wofsy (1996), Measurements of carbon sequestration by long-term eddy covariance: methods and a critical evaluation of accuracy. Glob. Change Biol., 2, 169-182.

Hunt, J. C. R., S. Leibovich, and K. J. Richards (1988), Turbulent shear flows over low hills. Quart. J. Roy. Meteorol. Soc., 114, 1435-1470.

Hunt, J. C. R. and K. J. Richards (1984), Stratified airflow over one or two hills. Boundary-Layer Meteorol., 30, 223-259.

Hunt, J. C. R., K. J. Richards, and P. W. M. Brighton (1988), Stably stratified shear flow over low hills. Quart. J. Roy. Meteorol. Soc., 114, 859-886. 
Hunt, J. C. R. and D. J. Carruthers (1990), Rapid distortion theory and the 'problems' of turbulence. J. Fluid Mech., 212, 497-532.

Inoue, E. (1963), On the turbulent structure of air flow within crop canopies. J. Meteor. Soc. Japan, 41, 317-326.

Jackson, P. S. and J. C. R. Hunt (1975), Turbulent wind flow over a low hill. Quart. J. Roy. Meteorol. Soc., 101, 929-955.

Kaimal, J. C. and J. J. Finnigan (1994), Atmospheric boundary layer flows: Their structure and measurements. Oxford University Press.

Kutsch, W. L., O. Kolle, C. Rebmann, A. Knohl, W. Ziegler, and E.-D. Schulze (2008), Advection and resulting $\mathrm{CO}_{2}$ exchange uncertainty in a tall forest in central Germany. Ecol. Appl., 18, 1391-1405.

Lalic, B. and D. T. Mihailovic (2002), A new approach in parameterization of momentum transport inside and above forest canopy under neutral conditions. Integrated Assessment and Decision Support, Proceedings of the1st biennial meeting of the International Environmental Modelling and Software Society, Switzerland, iEMSs: Manno, 139-154.

Landsberg, J. J. and G. B. James (1971), Wind profiles in plant canopies: Studies on an analytical model. J. Appl. Ecol., 8, 729-741.

Lee, X. (1998), On micrometeorological observations of surface-air exchange over tall vegetation. Agr. For. Meteor., 91, 39-49.

Lemon, E., L. H. Allen, and L. Muller (1970), Carbon dioxide exchange of a tropical rain forest. Bioscience, 20, 1054-1059. 
Legg, B. J. and I. F. Long (1975), Turbulent diffusion within a wheat canopy: results and interpretation. Quart. J. Roy. Meteor. Soc., 101, 611-628.

Mason P. J. and J. C. King (1984), Atmospheric flow over a succession of nearly twodimensional ridges and valleys. Quart. J. Roy. Meteor. Soc., 110, 821-845

Mason P. J. and R. I. Sykes (1979), Flow over an isolated hill of moderate slope, Quart. J. Roy. Meteor. Soc., 105, 383-395.

Massman, W. J. (1982), Foliage distribution in old-growth coniferous tree canopies. Can. J. For. Res., 12, 10-17.

Massman, W. J. (1987), A comparative study of some mathematical models of the mean wind structure and aerodynamic drag of plant canopies. Bound.-Layer Meteor., 40, 179-197.

Massman, W. J. (1997), An analytical one-dimensional model of momentum transfer by vegetation of arbitrary structure. Bound.-Layer Meteor., 83, 407-421.

Massman, W. J. and X. Lee (2002), Eddy covariance flux corrections and uncertainties in longterm studies of carbon and energy exchanges. Agr. For. Meteor., 113, 121-144.

Massman, W. J. and J. C. Weil (1999), An analytical one-dimensional second-order closure model of turbulence statistics and the lagrangian time scale within and above plant canopies of arbitrary structure. Bound.-Layer Meteor., 91, 81-107.

Meyers, T. and K. T. Paw U (1986), Testing of a higher-order closure-model for modeling airflow within and above plant canopies. Bound.-Layer Meteor., 37, 297-311.

Oliver, H. R. (1971), Wind Profiles In And Above A Forest Canopy. Quart. J. Roy. Meteor. Soc., $97,548-553$.

Pielke, R.A. (2002), Mesoscale meteorological modeling. 2nd Edition, Academic Press, San Diego, CA, 676 pp. 
Poggi, D. and G. G. Katul (2007a), An experimental investigation of the mean momentum budget inside dense canopies on narrow gentle hilly terrain. Agr. For. Meteor., 144, 1-13.

Poggi, D. and G. G. Katul (2007b), Turbulent flows on forested hilly terrain: the recirculation region. Quart. J. Roy. Meteor. Soc., 133, 1027-1039.

Poggi, D. and G. G. Katul (2007c), The ejection-sweep cycle over gentle hills covered with bare and forested surfaces. Bound.-Layer Meteor., 122, 493-515.

Poggi, D., G. G. Katul, J. J. Finnigan, and S. E. Belcher (2008), Analytical models for the mean flow inside dense canopies on gentle hilly terrain. Quart. J. Roy. Meteor. Soc., 134, 10951112.

Poggi, D. and G. G. Katul (2008), Turbulent intensities and velocity spectra for bare and forested gentle hills: flume experiments. Bound.-Layer Meteor., 129, 25-46.

Poggi, D., G. G. Katul, J. D. Albertson, and L. Ridolfi (2007), An experimental investigation of turbulent flows over a hilly surface. Phy. Fluids, 19, DOI: 10.1063/1.2565528

Queck, R. and C. Bernhofer (2010), Constructing wind profiles in forests from limited measurements of wind and vegetation structure. Agric. Forest Meteorol., 150, 724-735.

Ross, A. N. (2008), Large-eddy simulations of flow over forested ridges. Bound.-Layer Meteor., $128,59-76$.

Ross, A. N. and S. B. Vosper (2005), Neutral turbulent flow over forested hills. Quart. J. Roy. Meteor. Soc., 131, 1841-1862.

Ruck, B. and E. Adams (1991), Fluid mechanical aspects of the pollutant transport to coniferous trees. Bound.-Layer Meteor., 56, 163-195. 
Salmon, J. R., H. W. Teunissen, R. E. Mickle, and P. A. Taylor (1988), The kettles hill project: field observations, wind-tunnel simulations and numerical model predictions for flow over a low hill. Bound.-Layer Meteor., 43, 309-343.

Schlichting, H. (1960), Boundary layer theory. 4th ed. McGraw-Hill, 647 pp.

Shaw, R. H. (1977), Secondary wind speed maxima inside plant canopies. J. Appl. Meteor., 16, $514-521$.

Shaw, R. H. and U. Schumann (1992), Large-eddy simulation of turbulent flow above and within a forest. Bound.-Layer Meteor., 61, 47-64.

Staebler R. M., and D. R. Fitzjarrald (2004), Observing subcanopy $\mathrm{CO}_{2}$ advection. Agr. For. Meteor., 122, 139-156.

Su, H. B., R. H. Shaw, K. T. Paw, C.-H. Moeng, and P. P. Sullivan (1998), Turbulent statistics of neutrally stratified flow within and above a sparse forest from large-eddy simulation and field observations. Bound.-Layer Meteor., 88, 363-397.

Sun, J., S. P. Burns, A. C. Delany, S. P. Oncley, A. A. Turnipseed, B. B. Stephens, D. H. Lenschow, M. A. LeMone, R. K. Monson, and D. E. Anderson (2007), $\mathrm{CO}_{2}$ transport over complex terrain. Agr. For. Meteor., 145, 1-21.

Sun, J. and coauthors (2010), A multiscale and multidisciplinary investigation of ecosystematmosphere $\mathrm{CO}_{2}$ exchange over the Rocky Mountains of Colorado. Bull. Amer. Meteor. Soc., 91, 209-230.

Sutton, O. G. (1953), Micrometeorology: a study of physical processes in the lowest layers of the earth's atmosphere. McGraw-Hill Book Company, 333 pp.

Sykes, R. I. (1978), Stratification effects in boundary layer flow over hills. Proe. R. Soc. Lond. A 361, 225-243. 
Taylor, P. A. and H. W. Teunissen (1987), The askervein hill project: overview and background data, Bound.-Layer Meteor., 39, 15-39.

Tennekes, T. and J. L. Lumley (1972), A first course in turbulence, MIT press, 300pp.

Turnipseed, A. A., D. E. Anderson, P. D. Blanken, W. M. Baugh, and R. K. Monson (2003), Airflows and turbulent flux measurements in mountainous terrain Part 1. Canopy and local effects. Agr. For. Meteor., 119, 1-21.

von Kármán, T. (1930), Mechanische ähnlichkeit and yurbulenz. Nachr. Ges. Wiss. Göettingen Math. Phys. Kl., 68, 58-76.

Wang, W. (2010), The influence of topography on single-tower-based carbon flux measurements under unstable conditions: A modeling perspective. Theor. Appl. Climatol., 99, 125-138.

Wang, W. (2012), An analytical model for wind profiles in sparse canopies, Boundary-layer Meteorol., in press.

Wang, W. and M. Rotach (2010) Flux Footprints Over an Undulating Surface. Boundary-Layer Meteorol., 136(2), 325-340. doi: 10.1007/s10546-010-9498-8

Wang, W. and K. Davis (2008), A numerical study of the influence of a clearcut on eddycovariance flux measurements above a forest. Agr. For. Meteor., 148, 1488-1500. doi:10.1016/j.agrformet.2008.05.009.

Wang, W., K. Davis, B. D. Cook, C. Yi, P. S. Bakwin, M. P. Butler, and D. M. Ricciuto (2005), Surface layer $\mathrm{CO}_{2}$ budget and advective contributions to measurements of net ecosystematmosphere exchange of $\mathrm{CO}_{2}$. Agr. For. Meteor., 135, 202-214.

Wang, W., K. Davis, C. Yi, E. Patton, M. Butler, D. Ricciuto, and P. S. Bakwin (2007), A note on the top-down and bottom-up gradient functions over a forested site. Bound.-Layer Meteor., 124, 305-314 
Wang, W., K. Davis, D. M. Ricciuto, M. P. Butler, and B. D. Cook (2006), Decomposing $\mathrm{CO}_{2}$ fluxes measured over a mixed ecosystem at a tall tower and extending to a region: a case study. J. Geophys. Res., 111, G02005. DOI:10.1029/2005JG000093.

Wood, N. (2000), Wind flow over complex terrain: A historical perspective and the prospect for large-eddy modelling. Bound.-Layer Meteor., 96,11-32.

Wilson, J. D. (1988), A second-order closure model for flow through vegetation. Bound.-Layer Meteor., 42, 371-392.

Wilson, J. D., J. J. Finnigan, and M. R. Raupach (1998), A first-order closure for diturbed plantcanopy flows, and its application to winds in a canopy on a ridge. Quart. J. Roy. Meteor. Soc., $124,705-732$.

Wilson, J. D., D. P. Ward, G. W. Thurtell, and G. E. Kidd (1982), Statistics of atmospheric turbulence within and above a corn canopy. Bound.-Layer Meteor., 24, 495-519.

Wolfe, G. M., and J. A. Thornton (2011), The Chemistry of Atmosphere-Forest Exchange (CAFE) Model - Part 1: Model description and characterization, Atmos. Chem. Phys., 11, 77-101, doi:10.5194/acp-11-77-2011.

Wolfe, G. M., J. A. Thornton, M. McKay, and A. H. Goldstein (2011), Forest-atmosphere exchange of ozone: sensitivity to very reactive biogenic VOC emissions and implications for in-canopy photochemistry, Atmos. Chem. Phys. Discuss., 11, 13381-13424.

Wyngaard, J. L. (1973), On surface-layer turbulence. Workshop on Micrometeorology, Boston, American Meteorological Society, 101-149.

Yi, C. (2008), Momentum transfer within canopies. J. Appl. Meteor Climatol., 47, 262-275.

Yi, C. (2009), Instability analysis of terrain-induced canopy flows, J. Atmos. Sci., 66, 21342142, doi:10.1175/2009JAS3005.1. 
Yi, C., D. E. Anderson, A. A. Turnipseed, S. P. Burns, J. Sparks, D. Stannard, and K. R. Monson (2008), The contribution of advective fluxes to net ecosystem $\mathrm{CO}_{2}$ exchange in a highelevation, subalpine forest ecosystem. Ecol. Appl..

Yi, C., R. K. Monson, Z. Zhai, D. E. Anderson, B. Lamb, G. Allwine, A. A. Turnipseed, and S. P. Burns (2005), Modeling and measuring the nighttime drainage flow in a high-elevation, subalpine forest with complex terrain. J. Geophys. Res., 110, D22303, doi:10.1029/2005JD006282. 


\section{Caption:}

Fig. 1 (a) A sketch of the inner region $\left(z=0\right.$ to $h_{i}$ ) over a flat surface covered by a horizontallyhomogeneous plant canopy $(z=-h$ to 0$)$ and approximate balance equations within and above the canopy. $h$ is the canopy depth and $h_{i}$ is the height of the inner layer top. Above $h_{\mathrm{i}}$ is the outer region. (b) Over a hill. $F_{p}$ is the pressure gradient force, 'adv' stands for the advection terms, $H$ is the hill height, and $L_{h}$ is the hill half-length

Fig. 2 (a) Vertical profiles of wind velocities normalized by the background wind speed at the canopy top $U_{\mathrm{h}}$; (b) Vertical profiles of $\frac{\tau}{u_{*}^{2}}$.

Fig. 3 (a) LAD distributions in E1, E2, and E3. LAD is constant in E1. LAD varies with height in E2 and E3 based on Eq. 10, given LAI is equal to that in E1. The long dashed line is for E3 with $a=0.2$ and $b=1.63 \mathrm{~m}$ in Eq. 10 and dotted line is for E2 with $a=-0.2$ and $b=3.63 \mathrm{~m}$ in Eq. 10. (b) Vertical profiles of mean background wind speed in E1, E2, and E3.

Fig. 4 Vertical profiles of wind velocities at different locations in cases of three LAD distributions.

Fig. 5 The flow separation levels $\left(z_{\mathrm{d}}\right)$ as a function of horizontal distance from the hill crest in cases of three LAD distributions. 
Fig. 6 (a) Distribution of $C_{d}$ with height within the canopy derived from observations (cross symbols) at the Niwot Ridge AmeriFlux site in the Rocky Mountains of Colorado (Yi et al., 2005). $C_{\mathrm{d}}$ near the ground is derived from the logarithm function in the Appendix (dashed line). (b) LAD. $C_{\mathrm{d}}$ profile was interpolated based on observed data at a few levels (Yi et al., 2005).

Fig. 7 Background wind profiles for three scenarios of variations of $C_{\mathrm{d}}$ and LAD with height (E4, E5, and E6 in Table 2).

Fig. 8 Vertical profiles of wind velocities at different locations for three scenarios (E4, E5, and E6 in Table 2) of different variations of $C_{\mathrm{d}}$ and LAD with height. The canopy layer is shaded, with lighter colors representing smaller LAD values. 
(a)

$$
\mathrm{z}=h_{i}
$$

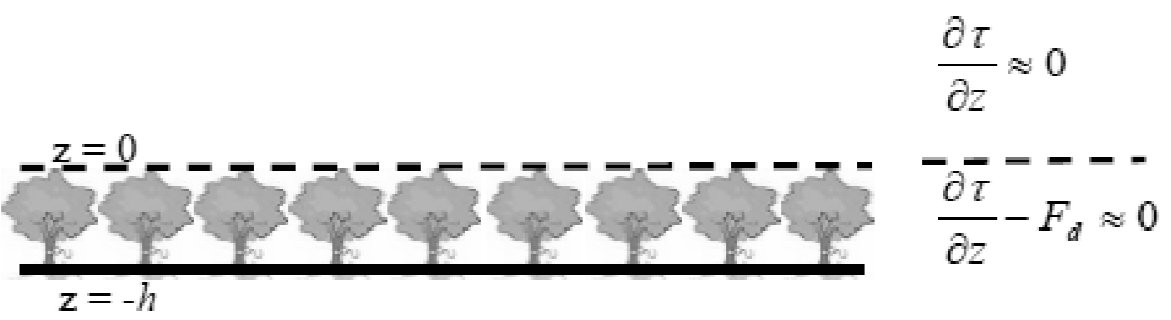

(b)

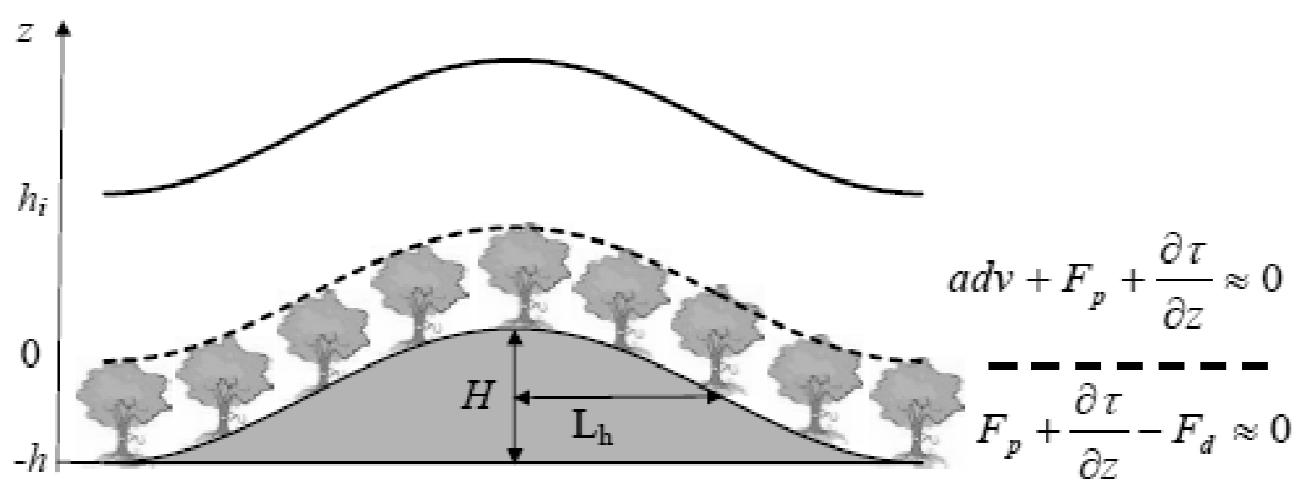

Fig. 1 (a) A sketch of the inner region $\left(z=0\right.$ to $h_{i}$ ) over a flat surface covered by a horizontallyhomogeneous plant canopy $(z=-h$ to 0$)$ and approximate balance equations within and above the canopy. $h$ is the canopy depth and $h_{i}$ is the height of the inner layer top. Above $h_{\mathrm{i}}$ is the outer region. (b) A sketch of wind flow over a canopy covered hill. $F_{p}$ is the pressure gradient force, 'adv' stands for the advection terms, $H$ is the hill height, and $L_{h}$ is the hill half-length 
(a)

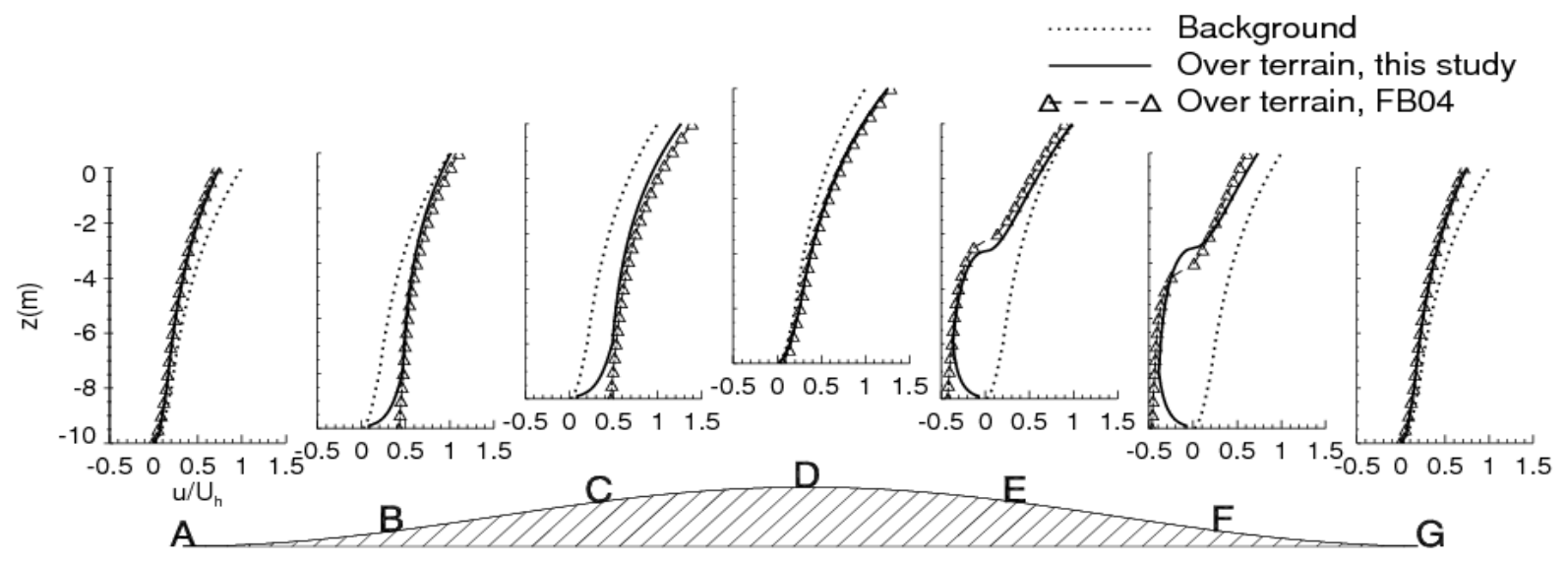

(b)

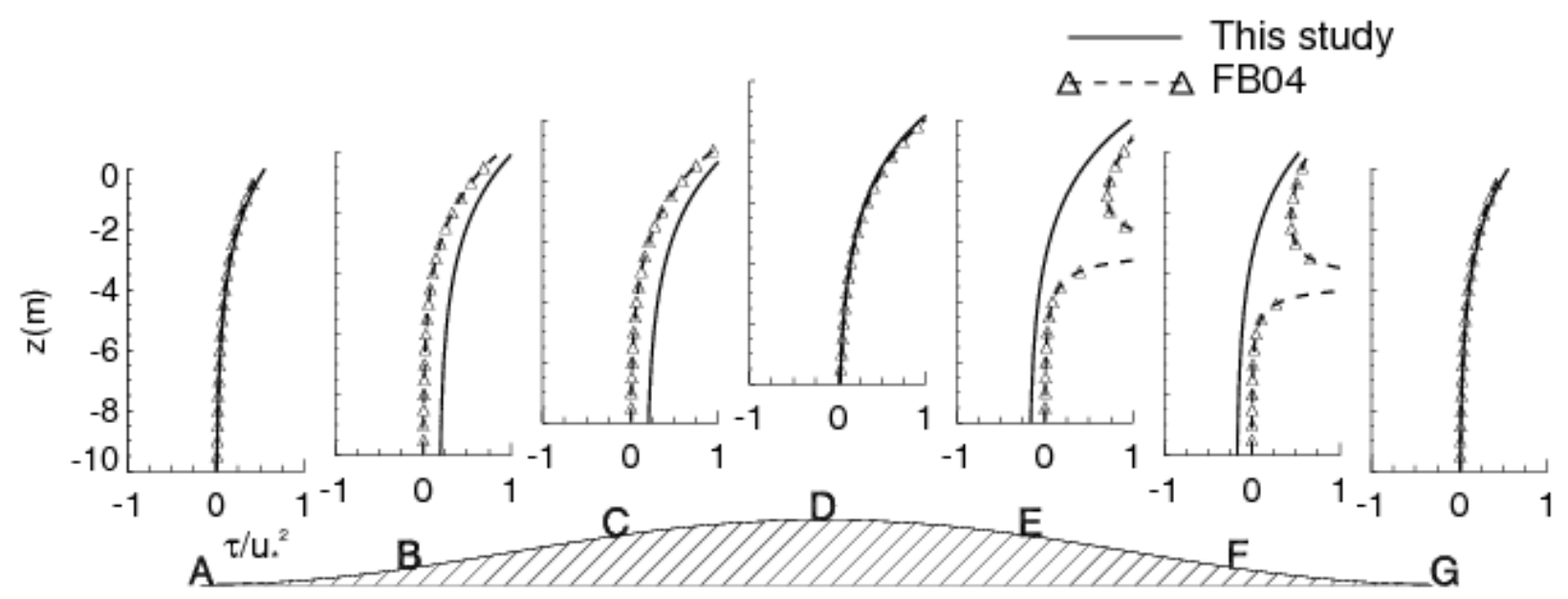

Fig.2. (a) Vertical profiles of wind velocities normalized by the background wind speed at the canopy top $U_{\mathrm{h}}$; (b) Vertical profiles of $\frac{\tau}{u_{*}^{2}}$. The canopy depth is $10 \mathrm{~m}$. 
(a)

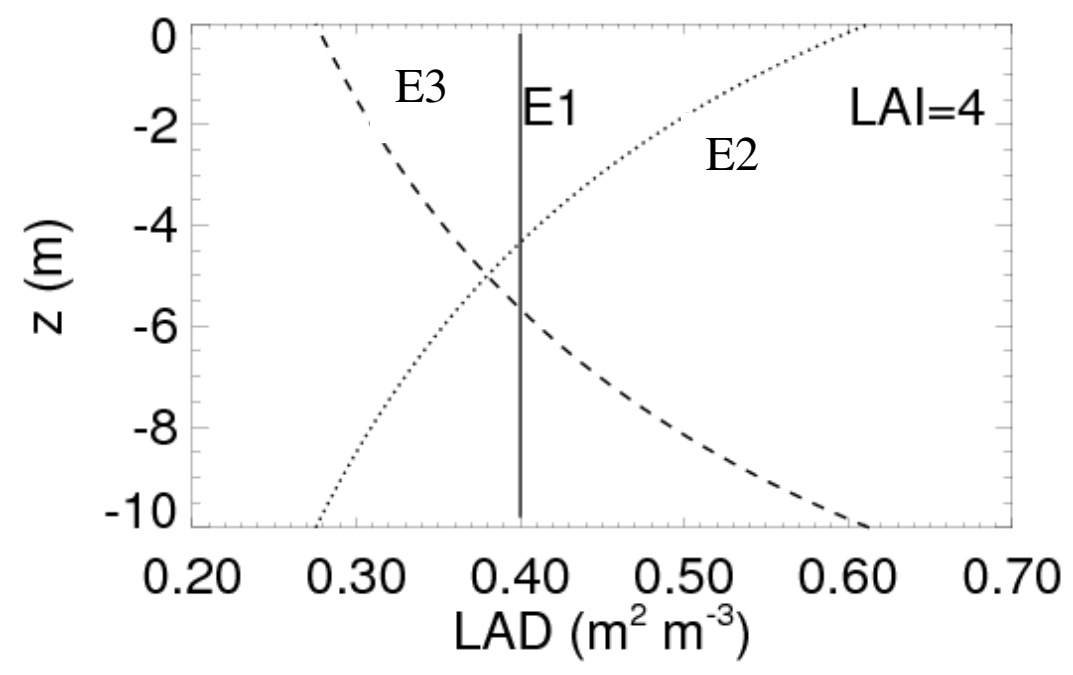

(b)

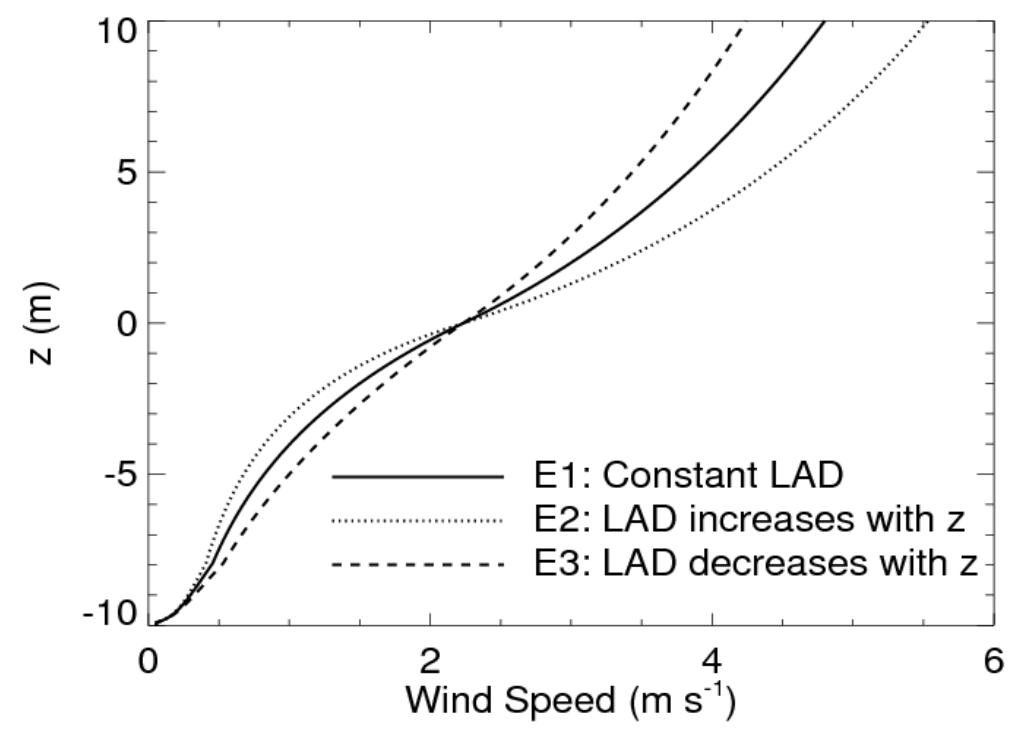

Fig. 3. LAD distributions in E1, E2, and E3. LAD is constant in E1. LAD varies with height in $\mathrm{E} 2$ and $\mathrm{E} 3$ based on Eq. 10, given LAI is equal to that in E1. The long dashed line is for E3 with $a=0.2$ and $b=1.63 \mathrm{~m}$ in Eq. 10 and dotted line is for E2 with $a=-0.2$ and $b=3.63 \mathrm{~m}$ in Eq. 10 . (b) Vertical profiles of mean background wind speed in E1, E2, and E3. 


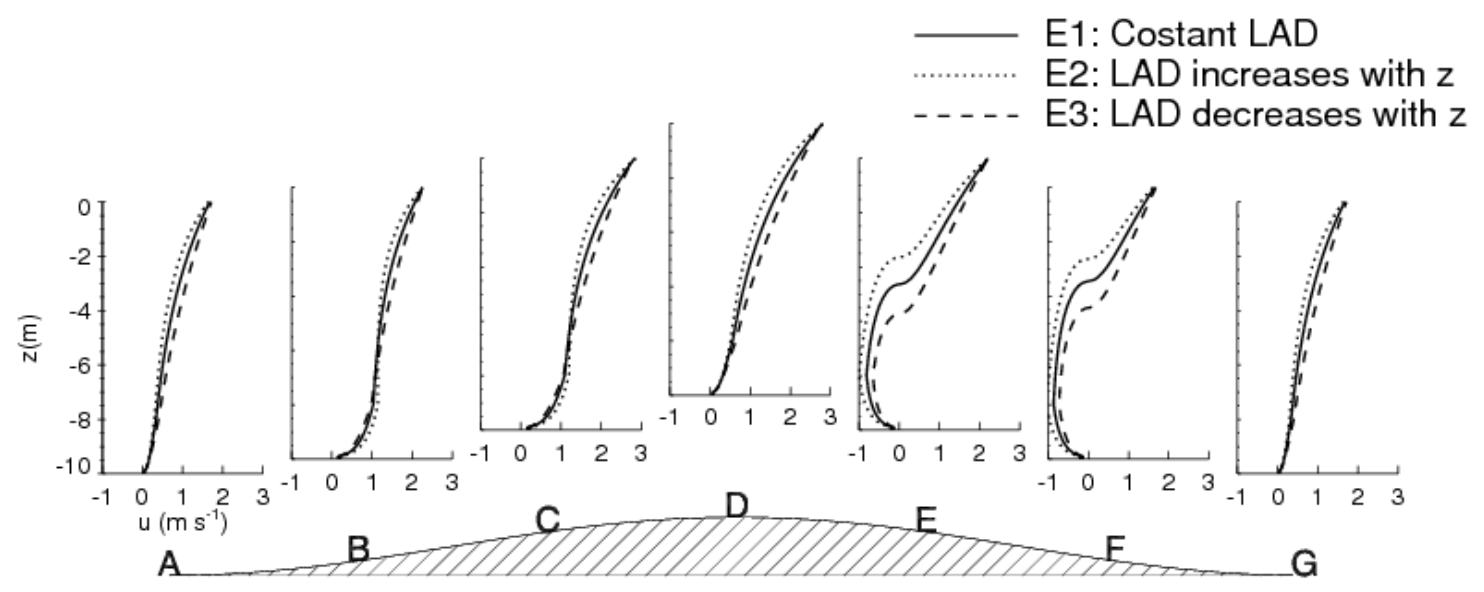

Fig. 4. Vertical profiles of wind velocities at different locations on the hill and the three scenarios of LAD distributions. 


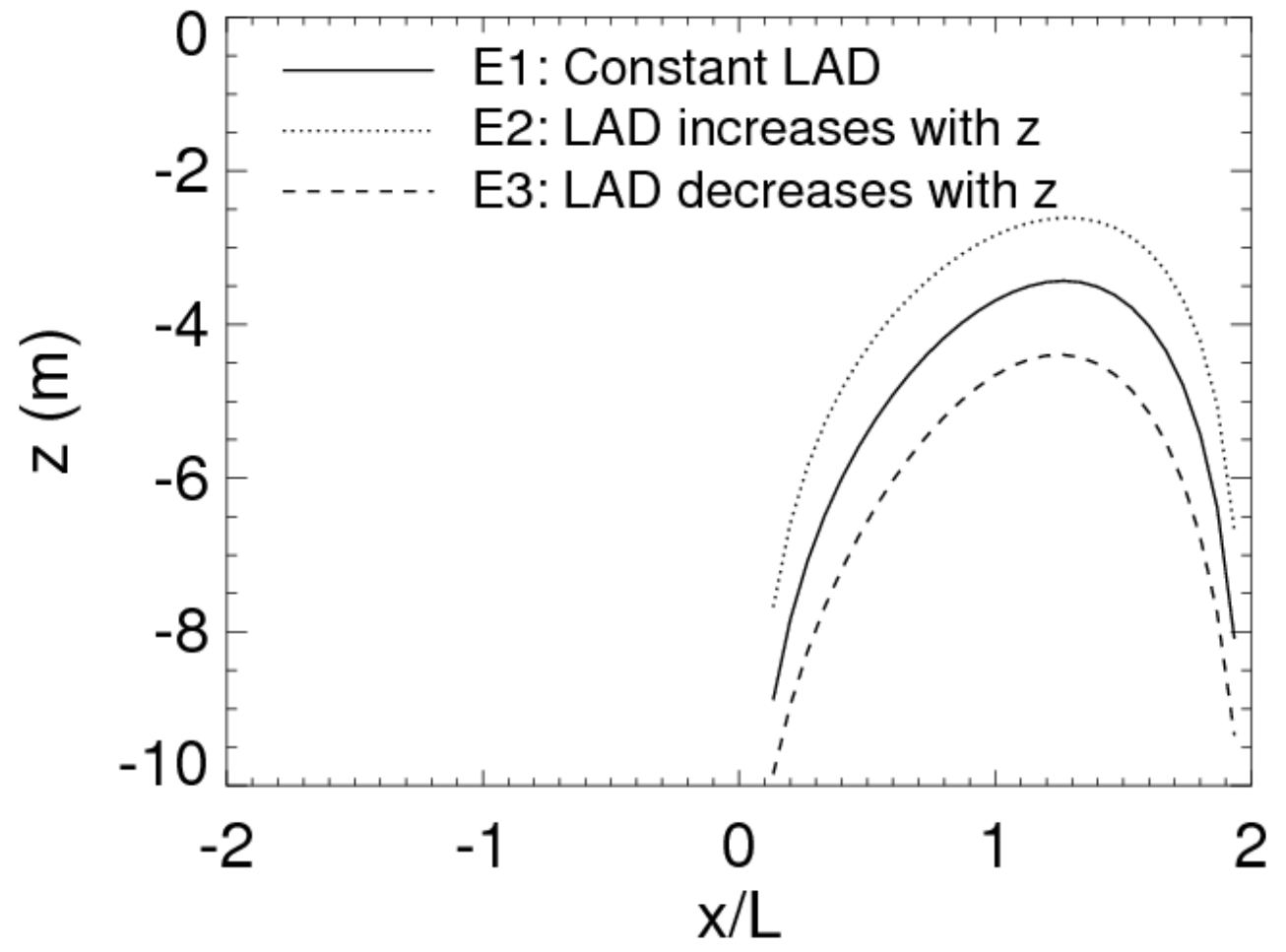

Fig. 5. The flow separation levels $\left(z_{\mathrm{d}}\right)$ as a function of horizontal distance from the hill crest in cases of three LAD distributions. 

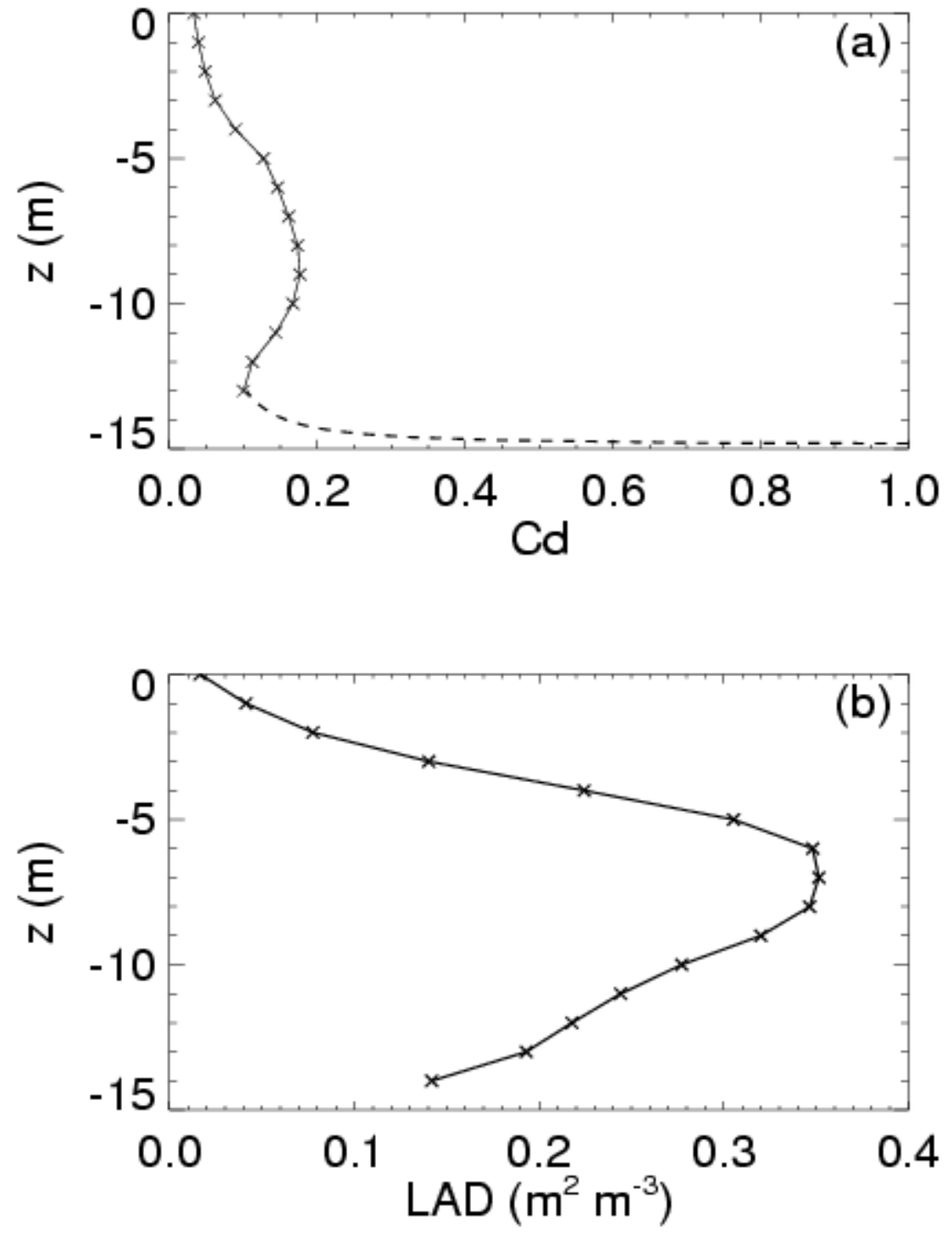

Fig. 6. (a) Distribution of $C_{\mathrm{d}}$ with height within the canopy derived from observations (cross symbols) at the Niwot Ridge AmeriFlux site in the Rocky Mountains of Colorado (Yi et al., 2005). $C_{\mathrm{d}}$ near the ground is derived from the logarithm function in Appendix (dashed line). (b) LAD. $C_{\mathrm{d}}$ profile was interpolated based on observed data at a few levels (Yi et al., 2005). 


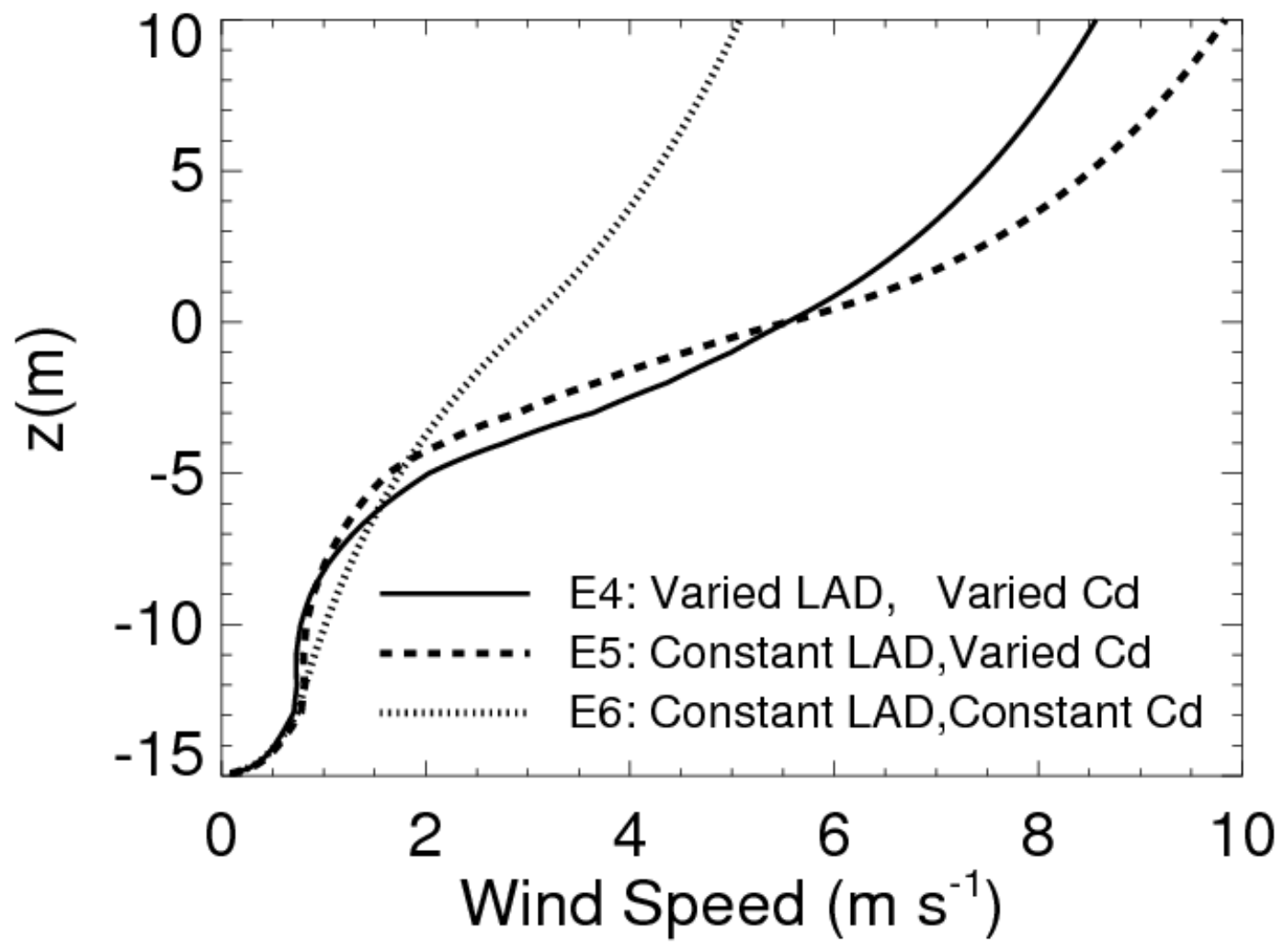

Fig. 7. Background wind profiles for three scenarios of variations of $C_{\mathrm{d}}$ and LAD with height (E4, E5, and E6 in Table 2). 


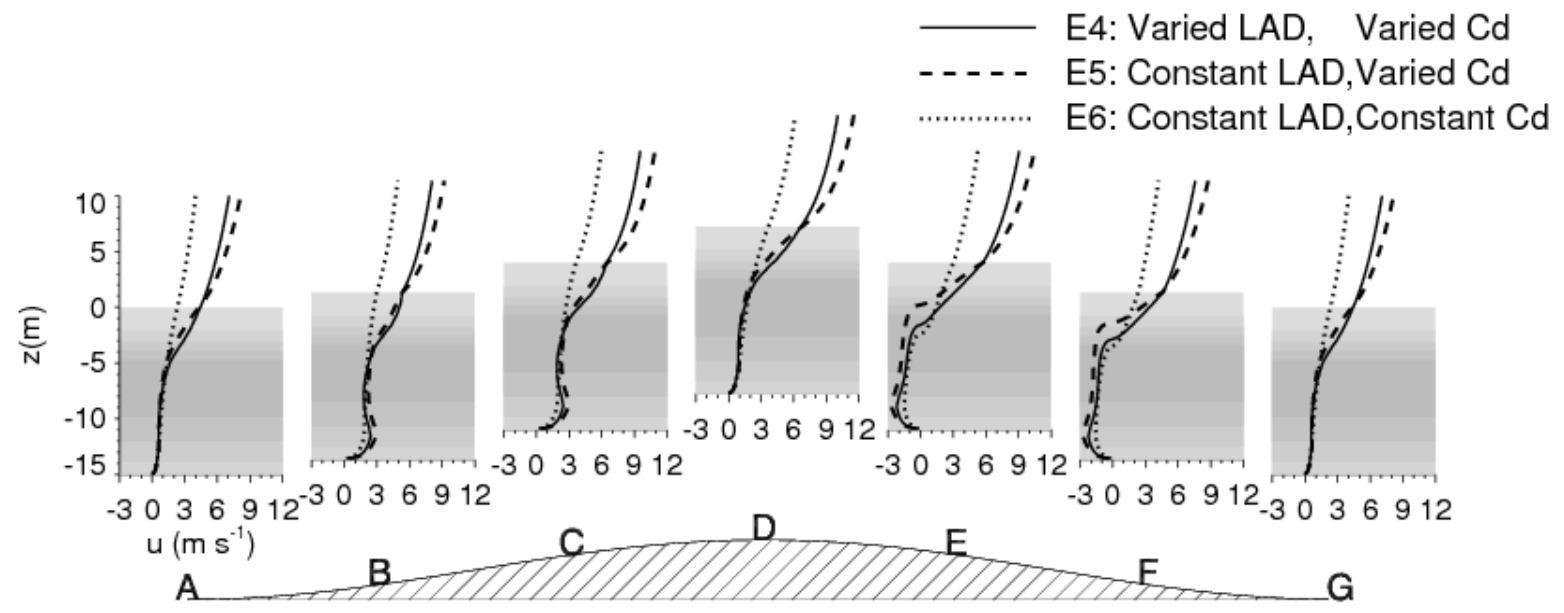

Fig. 8 Vertical profiles of wind velocities at different locations for three scenarios (E4, E5, and E6 in Table 2) of different variations of $C_{\mathrm{d}}$ and LAD with height. The canopy layer is shaded, with lighter colors representing smaller LAD values. 
Table 1. Comparison of treatments of canopy flow in this study and FB04

\begin{tabular}{|c|c|c|}
\hline Features & FB04 & This study \\
\hline Terrain and canopy & $\begin{array}{l}\text { Low slope terrain } H<<L_{\mathrm{h}} \\
L_{\mathrm{h}} \gg L_{\mathrm{c}}\end{array}$ & Same \\
\hline Coordinate system & Displaced & Same \\
\hline Advection & Neglected & Same \\
\hline $\begin{array}{l}\text { Topography-induced } \\
\text { Pressure }\end{array}$ & $\begin{array}{l}\text { Fixed through canopy in the } \\
\text { vertical }\end{array}$ & Same \\
\hline Balance equation & $\begin{array}{l}\text { Two-layer treatments } \\
\text { (1) Upper canopy levels, } \\
\Delta u<<U_{B} \text { is assumed. } \\
\text { Linear equation with three } \\
\text { terms balanced: pressure } \\
\text { gradient, stress gradient, } \\
\text { canopy drag } \\
\text { (2) Lower canopy levels, } \\
\text { stress gradient is neglected }\end{array}$ & $\begin{array}{l}\text { Directly solve a nonlinear } \\
\text { equation for } \mathrm{u}, \text { with } \\
\text { pressure gradient, stress } \\
\text { gradient, and canopy drag } \\
\text { terms balanced. } \\
\text { No need to assume } \Delta u<< \\
U_{\mathrm{B}}\end{array}$ \\
\hline $\begin{array}{l}\text { Turbulent stress } \\
\text { parameterization within } \\
\text { canopy }\end{array}$ & $\begin{array}{l}\text { Flux gradient theory with a } \\
\text { constant mixing length }\end{array}$ & $C_{\mathrm{d}} u|u|$ \\
\hline LAD & Constant with height & Varied \\
\hline No-slip on ground & $\mathrm{No}$ & Yes \\
\hline
\end{tabular}


Table 2. Parameters in different experiments

\begin{tabular}{|l|l|l|l|l|l|l|}
\hline $\begin{array}{l}\text { Experiment } \\
\text { ID }\end{array}$ & E1 & E2 & E3 & E4 & E5 & E6 \\
\hline $\begin{array}{l}\text { Canopy } \\
\text { depth }(\mathrm{m})\end{array}$ & 10 & 10 & 10 & 15 & 15 & 15 \\
\hline LAI & 4 & 4 & 4 & 3.3 & 3.3 & 3.3 \\
\hline LAD $\left(\mathrm{m}^{2} \mathrm{~m}^{-3}\right)$ & 0.4 & Increase & Decrease & Varied & 0.22 & 0.22 \\
\hline $\mathrm{C}_{\mathrm{d}}{ }^{-3}$ & 0.2 & 0.2 & 0.2 & Varied & Varied & 0.11 \\
\hline $\mathrm{d}(\mathrm{m})$ & 5.6 & 3.6 & 8.1 & 4.24 & 2.18 & 7.7 \\
\hline$z_{0}(\mathrm{~m})$ & 2.3 & 1.5 & 3.3 & 0.46 & 0.23 & 2.3 \\
\hline$h_{i}(\mathrm{~m})$ & 16 & 14 & 19 & 10 & 8.9 & 16 \\
\hline$h_{\mathrm{m}}(\mathrm{m})$ & 56 & 53 & 59 & 47 & 44 & 56 \\
\hline $\mathrm{U}_{0}\left(\mathrm{~m} \mathrm{~s}^{-1}\right)$ & 8 & 9 & 7.5 & 12 & 13 & 8 \\
\hline
\end{tabular}

${ }^{\#} \mathrm{C}_{\mathrm{d}}$ near the ground (below $2 \mathrm{~m}$ ) is treated as the log function of the distance from the ground (See Appendix) 